\title{
Correlation of SARS-CoV-2 to cancer: Carcinogenic or anticancer? (Review)
}

\author{
YING-SHUANG LI", HUA-CHENG REN ${ }^{*}$ and JIAN-HUA CAO \\ Intravenous Drug Administration Center, Department of Pharmacy, The Third People's Hospital \\ of Qingdao, Qingdao, Shandong 266041, P.R. China
}

Received April 25, 2021; Accepted December 15, 2021

DOI: 10.3892/ijo.2022.5332

\begin{abstract}
Severe acute respiratory syndrome coronavirus 2 (SARS-CoV-2) is highly infectious and pathogenic. Among patients with severe SARS-CoV-2-caused by corona virus disease 2019 (COVID-19), those complicated with malignant tumor are vulnerable to COVID-19 due to compromised immune function caused by tumor depletion, malnutrition and anti-tumor treatment. Cancer is closely related to the risk of severe illness and mortality in patients with COVID-19. SARS-CoV-2 could promote tumor progression and stimulate metabolism switching in tumor cells to initiate tumor metabolic modes with higher productivity efficiency, such as glycolysis, for facilitating the massive replication of SARS-CoV-2. However, it has been shown that infection with SARS-CoV-2 leads to a delay in tumor progression of patients with natural killer cell (NK cell) lymphoma and Hodgkin's lymphoma, while SARS-CoV-2 elicited anti-tumor immune response may exert a potential oncolytic role in lymphoma patients. The present review briefly summarized potential carcinogenicity and oncolytic characteristics of SARS-CoV-2 as well as strategies to protect patients with cancer during the COVID-19 pandemic.
\end{abstract}

\section{Contents}

1. Introduction

2. Tumor viruses

3. Is the SARS-CoV-2 carcinogenic?

4. Patients with COVID-19 with cancer

Correspondence to: $\mathrm{Dr}$ Jian-Hua Cao, Intravenous Drug Administration Center, Department of Pharmacy, The Third People's Hospital of Qingdao, 29 Yong Ping Road, Licang, Qingdao, Shandong 266041, P.R. China

E-mail: cao.jianhua@mau.edu.mk

*Contributed equally

Key words: severe acute respiratory syndrome coronavirus 2, corona virus disease 2019, patients with cancer, oncolytic virus
5. How to protect patients with cancer during the COVID-19 pandemic

6. Oncolytic virus and SARS-CoV-2

7. Conclusion

\section{Introduction}

Coronaviruses (CoVs) belong to the family Coronaviridae, a member of the order Nidovirales and exist widely in nature (1). Particles of CoVs with a diameter of $\sim 60-220 \mathrm{~nm}$ are spherical or oval in shape and display pleomorphism $(2,3)$. CoVs are enclosed by an envelope with spikes and have an internal genome comprising single stranded positive sense RNA (+ssRNA), while being named for their crown- or corona-like viral particles under the electron microscope (2). SARS-CoV-2 has been identified as the seventh coronavirus that is capable of infecting human beings and the remaining six CoVs are HCoV-229E, HCoV-OC43, HCoV-NL63, HCoV-HKU1, SARS-CoV and MERS-CoV (1,3-5). Compared with other CoVs, SARS-CoV-2 possesses higher infectivity and pathogenicity because some key sites within the receptor binding domain of spike protein on the surface of SARS-CoV-2 are different from other types of CoVs $(3,6,7)$. In February 2020, the World Health Organization termed SARS-CoV-2-infected pneumonia COVID-19 (8). A great number of patients with severe COVID-19 are either elderly individuals or complicated with other basic diseases. Particularly, patients with malignant tumor are vulnerable to the COVID-19 pandemic due to declined immune function caused by tumor depletion, malnutrition and anti-tumor therapy $(9,10)$. As a result, declined immune function could lead patients with cancer to be more susceptible to COVID-19 and to have a higher chance of developing a severe and critical illness with a poorer prognosis following COVID-19 infection. In addition, SARS-CoV-2 infection may elicit metabolic reprogramming in tumor cells and affect cancer progression (11). Notably, SARS-CoV-2-induced immune response could counteract NK/T cell lymphoma progression to a certain extent (12), suggesting that genetically modified SARS-CoV-2 may exhibit potential oncolytic characteristics. The present review examined the association of SARS-CoV-2 with cancer, providing new ideas to protect patients with cancer during the COVID-19 pandemic. 


\section{Tumor viruses}

What are 'tumor viruses'? In most cases, virus multiplication in host cells can block protein synthesis and DNA replication of the cells, leading to cell metabolism disorder, while massive replication of virus causes damage to numerous cellular organelles $(13,14)$. After the replication, large numbers of progeny viruses are then released from the cells, resulting in lytic cell death referred to as a destructive process $(14,15)$. Conversely, certain viruses known as 'tumor viruses' do not cause the destruction of infected host cells. Instead, tumor viruses can control the complex genome of host cells, promoting unrestricted cell proliferation (13-15). Experiments on induction of chicken sarcoma by Rous virus demonstrate that virus infection can successfully induce tumor formation $(16,17)$, showing that tumors can either develop spontaneously in organisms or be formed by virus induction. The above observation has laid a foundation for the following in vitro tumor cell cultures and in vivo transfection in mice. It has been shown that infection of Rous virus leads to the occurrence of tumor cell traits in the cultured cells in vitro, which include a loss of contact inhibition, continued proliferation and anchoring independence (17). To date, several tumor viruses have been identified, including human herpes virus 8 (HHV-8) (18-20), human papilloma virus (HPV) (19,21-27), hepatitis B virus (HBV) (19,28-30), Epstein-Barr virus (EBV) (19,26,31-35), Cytomegalovirus (CMV) (19,27,36-38), human immunodeficiency virus (HIV) (19,39-42), human T cell lymphotropic virus (HTLV) $(43,44)$ and hepatitis C virus (HCV) (45-48) (Fig. 1).

Oncogenic mechanism of tumor viruses. Viruses have a very small genome in which most genes encode proteins involved in virus replication, while only a very small portion of the genes may be related to tumor cell transformation (27). The carcinogenic mechanism of tumor viruses has not yet been fully elucidated, which may be related to the destruction of host cell genetic stability, cell gene phenotype changes and virus latency/reactivation. These mechanisms are not independent and there are complex connections between them. Although different tumor viruses encode different virus products, they can target some of the same mechanisms, such as inhibiting tumor suppressor gene expression, abnormally activating oncogenes to interfere with cell growth and differentiation-related signals including NF- $\mathrm{BB}$, telomerase reverse transcriptase (TERT), tumor necrosis factor receptor associated factors (TRAFs), PI3K-AKT-mTOR, $\beta$-catenin and interferon signaling pathway, thereby affecting cell growth cycle regulation and inducing malignant cell transformation (49-51). DNA viruses encode viral oncogenes and RNA viruses can directly encode oncogenes or activate cell oncogenes through cis- or trans activation. Centrifugation-based measurement of the molecular mass of nucleic acids reveals that viral nucleic acid sequences co-sediment with host nucleic acid macromolecules, indicating that viral nucleic acids have become integrated into host chromosomes, constituting the cellular genome (52). It is noteworthy that instead of the whole nucleic acid sequence of viruses, only a part of the sequence with oncogenic role becomes integrated into the cellular genome. In these cases, part of single-strand RNAs in the genome of RNA viruses are reverse-transcribed into double-strand DNAs that are subsequently integrated into host chromosomal DNAs. These integrated viral double-strand DNAs are known as proviruses (53).

The genome of organisms harbors a large number of proto-oncogenes, such as Myc, c-Kit, Raf, Ret, H-ras and K-ras (54-58). Among $>30$ proto-oncogenes identified to date, most have derived their names from the respective viruses in which they were originally discovered. Once proto-oncogenes in the genome of organisms are captured and activated by the respective viruses, malignant transformation of cells will occur (59). Retroviruses containing oncogenes can capture and activate proto-oncogenes. By contrast, retroviruses without oncogenes activate proto-oncogenes by inserting their own genomes adjacent to those genes (insertion mutations) (60). It has been demonstrated that this insertion is not random and the insertion sites of retrovirus double-strand DNAs (proviruses) are closely adjoined to the proto-oncogenes (60), suggesting the presence of a mechanism underlying the recognition of proto-oncogenes in retroviruses. Under this circumstance, integrated transcriptional promoter of the viral genome causes a damage to the regulatory mechanism of proto-oncogene expression, enabling the expression of cellular genes under the control of the viral promotor and eliciting a constitutive expression of proto-oncogenes (61-63).

In addition to changes in proto-oncogenes and tumor suppressor genes, the origin of tumors also includes the effects on host cell gene stability and gene phenotype. Tumor viruses can inhibit the expression of host tumor suppressor genes and interfere with cell cycle regulation by affecting the form of DNA methylation and histone modification $(64,65)$. In addition, the virus has caused damage to cells before entering the incubation period, resulting in permanent genetic and epigenetic changes in the cells; the virus entering the incubation period may reactivate and cause damage to the cell (64.65). The virus may experience latency/reactivation cycle changes and the cells surviving continuous damage continue to accumulate DNA damage during this period and then a series of effects such as genetic instability, cell immortalization and tumors occur (66).

\section{Is the SARS-CoV-2 carcinogenic?}

The novel coronavirus SARS-CoV-2 belongs to the $\beta$-coronaviruses genus, has an envelope, is $60-140 \mathrm{~nm}$ in diameter and round or oval in shape (62). SARS-CoV-2 virus is sensitive to ultraviolet and heat and can be effectively inactivated by heating at $56^{\circ} \mathrm{C}$ for $30 \mathrm{~min}$ or treatment with numerous lipid solvents including ether, $75 \%$ ethanol, chlorine containing disinfectant, peracetic acid and chloroform. At present, epidemiological investigation and research reveal that the incubation period of SARS-CoV-2 lasts 1-14 days, generally 3-7 days $(67,68)$. Individuals infected with SARS-CoV-2 are highly infectious $1-2$ days before the onset and at the early stage of the disease, while patients infected with SARS-CoV-2 and asymptomatic infected persons are considered the main source of infection (68). Respiratory droplets and close contact transmission have been found to be the main transmission routes. In addition, while contact with virus contaminated items may lead to infection, there is the possibility of aerosol 


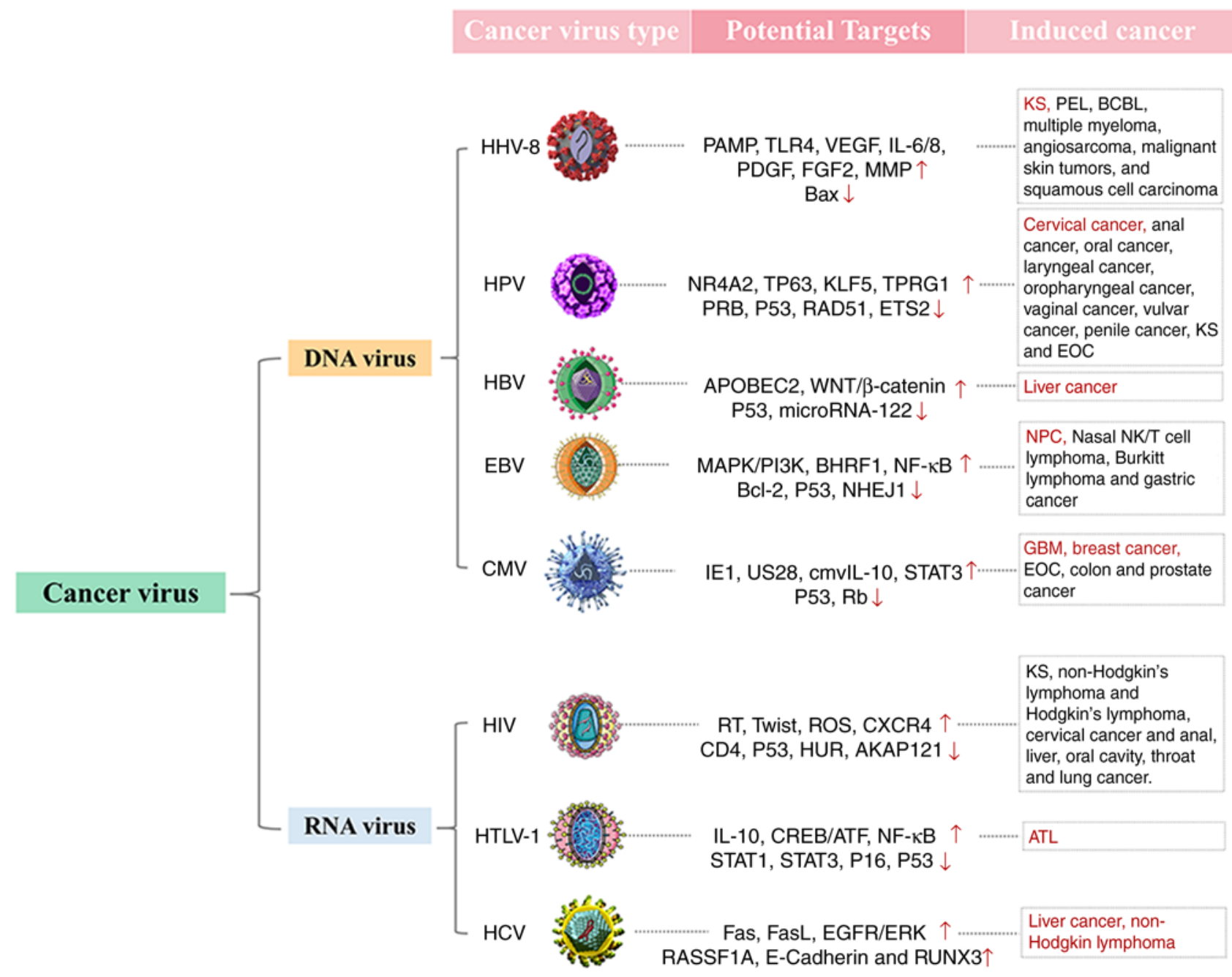

Figure 1. Tumor viruses and their potential anti-tumor targets so far identified. Up arrow and down arrow represent respectively excitory and inhibitory effects of tumor viruses on relevant targets. Red color highlights several types of cancers with the highest sensitivity to tumor viruses. KS, Kaposi's sarcoma; PEL, primary exudative lymphoma; BCBL, body cavity-based lymphoma; EOC, epithelial ovarian cancer; NPC, nasopharyngeal carcinoma; GBM, glioblastoma multiforme; ATL, adult T-cell leukemia.

transmission under the condition of long-term exposure to high concentration of aerosol in a relatively closed environment (69-71). Given that SARS-CoV-2 has been isolated from feces and urine, attention should be paid to contact or aerosol transmission caused by environmental pollution of feces and urine. SARS-CoV-2 is highly infectious and the total number of infected individuals is now $>290$ million $(71,72)$. In the meantime, over 5.4 million individuals have succumbed to SARS-CoV-2-caused COVID-19 worldwide (Fig. 2). Similar to tumor viruses, SARS-CoV-2 may accelerate tumor progression by altering the metabolic pathways of tumor cells. It has been shown that SARS-CoV-2 infection of human colon epithelial carcinoma cell line Caco-2 remodels the central cell pathways, including translation, splicing, carbon metabolism and nucleic acid metabolism, while small molecule inhibitors targeting the aforementioned pathways are capable of inhibiting the replication of SARS-CoV-2 in Caco-2 cells (73). For example, nucleic acid metabolism inhibitor Ribavirin can suppress the replication of SARS-CoV-2 at a low molar concentration $(73,74)$. In addition, the proteomics of Caco- 2 cells undergo an extensive regulation after $24 \mathrm{~h}$ of SARS-CoV-2 infection, which mainly involves a decrease in cholesterol rich metabolic proteins and an increase in carbohydrate metabolism-modifying proteins during the infection (73). Studies imply that SARS-CoV-2 may stimulate metabolism switch in tumor cells to initiate metabolic modes with higher productivity efficiency, such as glycolysis, for facilitating the massive replication of SARS-CoV-2 $(75,76)$. In this case, inhibiting glycolysis metabolism in tumor cells using 2-DG, a hexokinase inhibitor, can significantly suppress the replication of SARS-CoV-2 in Caco-2 cells $(73,75)$. This suggests that SARS-CoV-2 infection may elicit metabolic reprogramming in tumor cells, thereby affecting cancer progression (Fig. 3).

\section{Patients with COVID-19 and cancer}

The risk of developing a severe illness in patients with COVID-19 complicated with malignancy is 3.61 times as high as that in those without malignancy (77). Recently, epidemiological studies of COVID-19 conducted in New York tertiary health cancer center revealed that $56 \%$ of patients with COVID-19 are adults aged $>60$, while the most common malignancies involved include numerous solid tumors such as breast cancer, colorectal cancer and lung cancer (78). Lymphoma is 

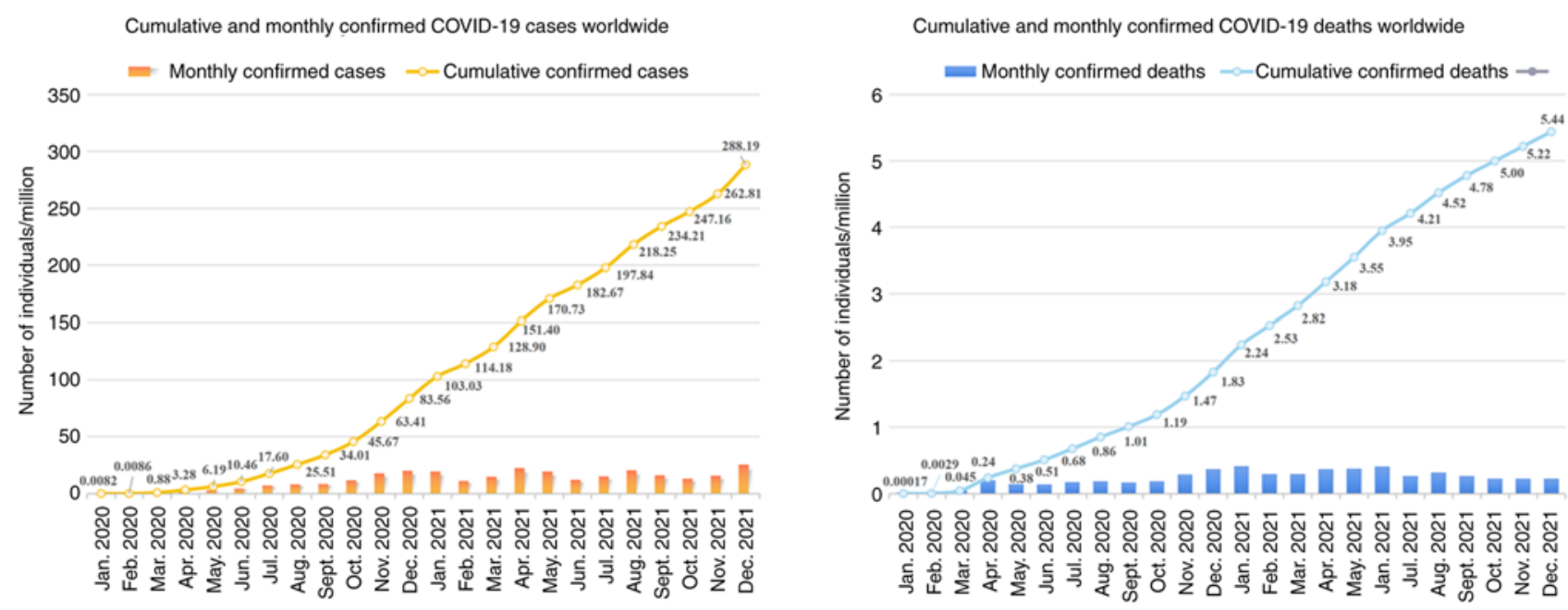

Figure 2. Cumulative and monthly confirmed COVID-19 cases and deaths worldwide. The confirmed counts shown here are lower than the total counts. The main reason for this is limited testing and challenges in the attribution of the cause of death. The source of the data is from COVID-19 data repository by the Center for Systems Science and Engineering at Johns Hopkins University. COVID-19, corona virus disease 2019.

the most prevalent hematopoietic malignancy and $>50 \%$ the cases are metastatic solid tumors $(78,79)$. Among patients with cancer and COVID-19, 59\% had at least one of the designated complications, including diabetes, hypertension, chronic kidney disease and heart disease (77). Adjuvant therapeutic drugs currently used in clinic include hydroxychloroquine, azithromycin, redcivir, tosilizumab, recovery plasma and corticosteroids (80-84). Patients with hematological cancer and SARS-CoV-2 infection exhibit a higher rate of mortality compared with patients infected with SARS-CoV-2 and with other types of cancer, since malignant or dysfunctional plasma cells, lymphocytes or white blood cells present in hematopoietic malignancies (leukemia, myeloma and lymphoma) can reduce the immune function of organisms (85).

Among all solid tumors, lung cancer has been shown to be the most dangerous class of diseases to patients infected with SARS-CoV-2 (85). For patients with COVID-19 complicated with lung cancer, fever and cough are the most obvious clinical symptoms, while the most significant features of computerized tomography (CT) imaging include ground glass shadow and patchy shadow (85). In addition, laboratory examination reveals that patients with COVID-19 complicated with malignancy, particularly those critical cases, clearly manifest cytokine storm, immune system dysfunction and multiple organ/system damage including a relatively prominent coagulation disorder (86). The risk factors for developing a severe COVID-19 case include old age, IL-6, procalcitonin, increased D-dimer, declined lymphocytes, cancer type, cancer staging and cancer treatment (87-89). According to the data analysis of 7,094 Chinese patients with COVID-19 with an average age of 50, the cancer prevalence in COVID-19 population is $2.3 \%$, which is four times higher compared with that in the entire Chinese population $(0.26 \%)$ and also three times higher compared with that in the 50-year-old Chinese population $(0.39 \%)(90)$. This suggests that tumors are closely associated with the risk of severe illness and death in patients with COVID-19. Notably, no difference in the fatality rate or severity of COVID-19 was observed between patients with cancer at an early stage without tumor metastasis and non-cancer patients (85). Conversely, patients with advanced metastatic cancer are more likely to be infected with SARS-CoV-2 (85).

It has also been reported that patients with cancer and COVID-19 display a poor prognosis; this observation was more evident in those with hematological malignancy and a higher risk of death was found in male patients (91). Chemotherapy administered four weeks before the onset of symptoms and being male are considered the high-risk factors for COVID-19 infection in patients with cancer. Among 182 patients with COVID-19 and a complete history of tumor therapy, 31 underwent chemotherapy within 4 weeks prior to being infected with COVID-19 (91). Markedly, the mortality risk of the 31 patients was 3.51 times as high as that of the remaining 151 patients. A relative low mortality was detected in patients with COVID-19 with frequently occurring cancer in women, such as breast cancer, thyroid carcinoma and cervical cancer (91). Conversely, the mortality risk of male patients with cancer infected with COVID-19 was 3.86 times as high as that of the female counterparts (91).

\section{How to protect patients with cancer during the COV- ID-19 pandemic}

Postponing targeted therapy or immunotherapy accordingly. Given that patients with cancer and COVID-19 are characterized by high mortality (92), it is recommended that these patients continue to take anticancer drugs orally during the COVID-19 pandemic. However, the antitumor therapy should be undertaken carefully and reasonably, while postponing adjuvant chemotherapy or selective operation needs to be considered on a discretionary basis to avoid the aggravation of pneumonia symptoms (93). In addition, it has been shown that patients with COVID-19 and a history of cancer who are undergoing an active treatment have a higher risk of developing a severe event than those without cancer (94). It is noteworthy that during the hospitalization, the mortality risk of those patients recently undergoing antitumor therapy is 4 times as 


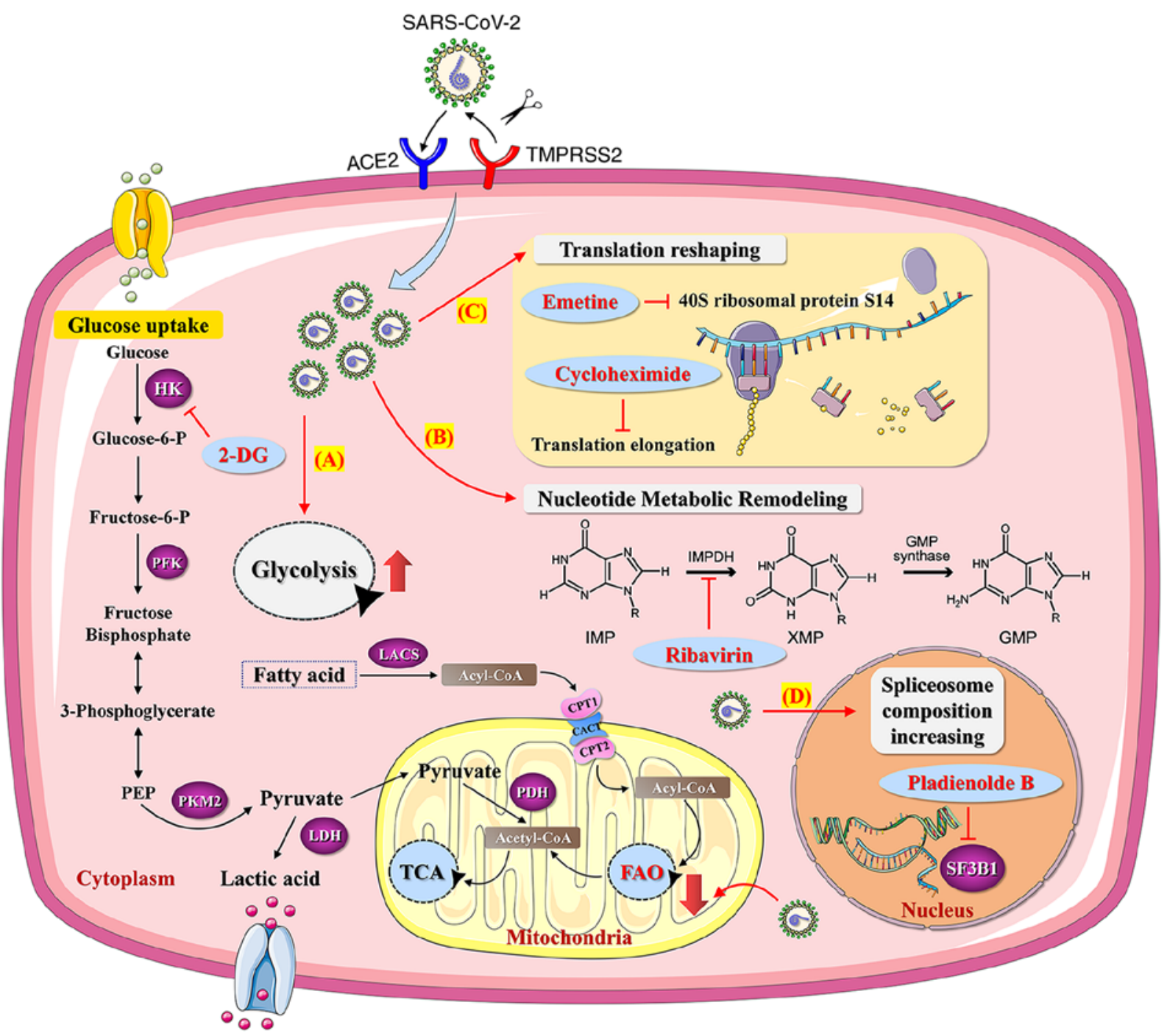

Figure 3. Effects of SARS-CoV-2 on metabolism pathways of tumor cells and potential metabolic targets for inhibiting SARS-CoV-2 replication in tumor cells. (A) SARS-CoV-2 may increase the rate of tumor productivity by increasing the metabolic ratio of glycolysis/FAO in tumor cells. The application of 2-DG, a hexokinase (rate-limiting enzymes of glycolysis) inhibitor, may suppress the replication of SARS-CoV-2 in tumor cells. (B) SARS-CoV-2 can induce tumor nucleotide metabolic remodeling. The application of Ribavirin may suppress the replication of SARS-CoV-2 in tumor cells. (C) SARS-CoV-2 can induce tumor translation reshaping. The application of Emetine and Cycloheximide may suppress the replication of SARS-CoV-2 in tumor cells. (D) SARS-CoV-2 can increase tumor spliceosome composition. The application of SF3B1 inhibitor may suppress the replication of SARS-CoV-2 in tumor cells. SARS-CoV-2, Severe acute respiratory syndrome coronavirus 2; HK, hexokinase; PFK, phosphofructokinase; PKM2, pyruvate kinase isozyme type M2; LDH, lactate dehydrogenase; LACS, long chain long-chain acyl-CoA synthetase; CPT, carnitine palmitoyltransferase; CACT, carnitine-acylcarnitine translocase; FAO, fatty acid oxidation; PDH, pyruvate dehydrogenase; TCA, tricarboxylic acid cycle; ACE2, angiotensin converting enzyme 2; TMPRSS2, transmembrane protease serine 2; IMPDH, inosine monophosphate dehydrogenase; IMP, hypoxanthine ribonucleotide; XMP, xanthosine monophosphate; GMP, guanosine 5'-monophosphate; 2-DG, 2-Deoxy-D-glucose.

high as that of general population (88). In addition, targeted therapy or immunotherapy could lead to a 3.29 -fold increase in the risk of developing a severe and critical COVID-19 (88). Notably, among all patients with COVID-19 and cancer receiving various therapies, those undergoing immunotherapy displayed the highest mortality rate as well as the most severe case (88). This increase can be attributed to the enhancement in immune system-mediated attack against SARS-CoV-2 in the later stage of the virus infection, which aggravates the lung damage and then elicits severe symptoms (Fig. 4) (95). In addition, pneumonia accounts for $42 \%$ of all death cases caused by the side effects of programmed death-1 (PD-1) antibodies (96). Similarly, either autologous and allogeneic hematopoietic stem cell transplantation or chimeric antigen receptor T cell therapy may lead patients with cancer to be highly susceptible to SARS-CoV-2 infection (88).

By contrast, it has also been demonstrated that blockage of PD-1/PDL-1 pathway can inhibit acute or chronic viral infection to a certain extent. An elderly patient infected with SARS-CoV-2 took nivolumab for metastatic malignant melanoma in the meantime. Surprisingly, considering her age, complications and cancer diagnosis, her virus infection condition was well controlled and no pneumonia was developed (97). This may be attributed to nivolumab-induced blockage of PD-1/PDL-1 pathway and its anti-viral effect. In addition, use of immune checkpoint inhibitors (ICIs) for the cancer treatment is getting more and more prevalent. However, ICI-caused recovery of immune function in patients 


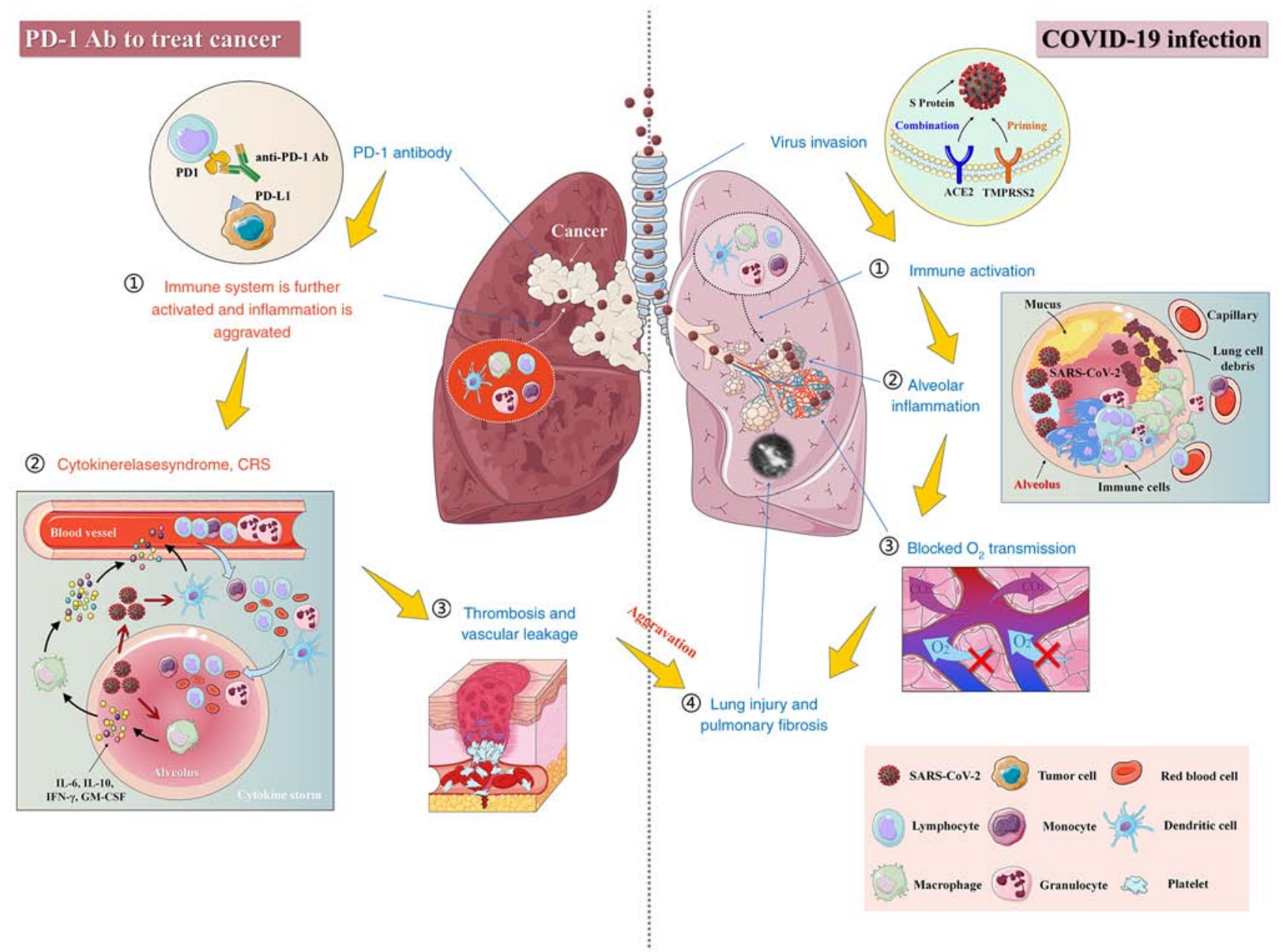

Figure 4. Potential immune risks associated with the application of PD-1 antibodies to treat patients with cancer complicated with a severe COVID-19. Administration of PD-1 antibodies to patients with cancer and severe COVID-19 for an antitumor therapy may result in increased attack against the host cells harboring the viral components due to the activated immune system and even initiate the cytokine storm, thereby promoting inflammation and lung toxicity. COVID-19, corona virus disease 2019; SARS-CoV-2, Severe acute respiratory syndrome coronavirus 2; PD-1, Programmed death-1.

with cancer may lead to generation of potential lung toxicity, thus aggravating COVID-19 and acute respiratory distress syndrome (ARDS) $(98,99)$. Tocilizumab has been shown to be successfully applied for treatment of the immune-related adverse event (irAE), such as arthritis in patients undergoing ICI treatment (100). As a monoclonal antibody raised against IL-6 receptor, tocilizumab may serve as a potential neutralizing antibody for COVID-19 treatment $(95,101,102)$. Thus, the study of ICI and tocilizumab may provide some new thoughts for overcoming the side effects of irAEs in patients with cancer and COVID-19. In addition, the PD-1 block did not appear to affect the severity of COVID-19 in lung patients with cancer after the risk factors for smoking were excluded (103). Despite all these observations, whether or not ICIs including PD-1 antibody should be given to patients with cancer during SARS-CoV-2 infection needs to be determined based on larger scale clinical analysis, including the perspectives of immune function of patients, tumor type, tumor stage, antiviral efficacy of drugs and so forth. For patients who need to receive cancer treatments, assessment of the immune function of patients based on immune deficiency score index, strengthening nursing care of patients prior to the recovery of immune function and early vaccination against respiratory pathogens, such as seasonal influenza and streptococcus pneumoniae, should be carried out (104).

Conducting chemotherapy preferentially using drugs with low risk of immunosuppression and oral dosage forms. During the COVID-19 pandemic, chemotherapy can only be applied to patients with cancer unless immunosuppression, blood toxicity, pneumonia/interstitial lung disease and other serious risks caused by chemotherapy are reduced (94). For example, when chemotherapy regimens with moderate/high risk of immunosuppression (e.g. anthracyclines, docetaxel, cisplatin or carboplatin 3 times a week) are administered to patients with triple-negative breast cancer, it is recommended that the patients should be supplemented with preventive hematopoietic growth factors to reduce the risk of suffering from neutropenia (105). Application of steroids needs to be strictly controlled to prevent an increased risk of immunosuppression. During the pandemic, the oral preparation is usually the first choice for adjuvant bisphosphonates. Low-dose oral medication such as capecitabine and vinorelbine should be considered preferentially in choosing the chemotherapy regimen for avoiding hematological toxicity (94). In case intravenous injection is considered 
unavoidable, preferential use of liposome preparation of anthracyclines and prolonged dosing interval of intravenous injection should be applied.

Employing hypofractionated radiotherapy (RT-hypo) or short fractionated radiotherapy to treat non-metastatic cancer. It has been suggested that during the COVID-19 outbreak, RT-hypo can be applied for the treatment of neck squamous cell carcinoma (HNSCC) patients with a relatively lower risk of distant metastasis (106). It is proposed that RT-hypo be considered in place of concurrent chemoradiotherapy for HPV+T1-T3N0-N2c (TNM-7) HNSCCs, HPV-T1-T2N0 HNSCCs and selected stage III HNSCCs during the outbreak (106). When shorter and fewer hospital visits, as well as avoidance of immunosuppressive chemotherapy, are needed to reduce the risk of SARS-CoV-2 infection, RT-hypo or short fractionated radiotherapy may provide a more appropriate regimen for patients with non-metastatic cancer. Therefore, it is necessary to assess the risk of disease progression for those patients who do not receive a timely and effective antitumor therapy. In this case, a timely diagnosis and tumor treatment should be applied to those patients with a rapidly progressed cancer such as lung cancer, pancreatic cancer, leukemia and highly invasive lymphoma. By contrast, targeted tumor therapy may be postponed for patients with thyroid carcinoma, breast cancer, or other carcinoma at a relatively low risk of disease progression. Particularly, for hospitalized elder tumor patients with COVID-19 or patients complicated with other basic diseases, early clinical monitoring should be strengthened, while timely and effective tumor intervention measurements need to be formulated. If possible, priority should be given to minimally invasive surgery because compared with open surgery, minimally invasive surgery can shorten the duration of hospitalization and improve the recovery of patients with cancer, thereby reducing the risk of SARS-CoV-2 infection in hospital (67).

Downregulating the expression of TMPRSS2 through inhibiting androgen receptor signaling. Some evidence suggests that therapeutic drugs for prostatic cancer may serve a synergistic role in treating COVID-19 (107). Inhibition of androgen signaling is considered the symbolic therapeutic strategy of prostatic cancer, while androgen inhibitors (e.g. leuprolide) and androgen receptor (AR) signaling inhibitors (e.g. enzalutamide, apalutamide and darolutamide) constitute the basis for the treatment of prostate cancer (107). In particular, either inhibition of AR expression and transcription or blockade of CYP17 using abiraterone provide a new perspective for the treatment of hormone-independent prostatic cancer (107). Transmembrane serine protease 2 (TMPRSS2) and angiotensin-converting enzyme 2 (ACE2) have been identified as the key targets for enhanced entry of SARS-CoV-2 into host cells $(72,108,109)$. In addition, AR signaling has been demonstrated to promote the expression of TMPRSS2 (107). Thus, inhibition of AR signaling for treating prostatic cancer may suppress infection of SARS-CoV-2 in host cells by downregulating TMPRSS2, thereby preventing and treating COVID-19 (Fig. 5). However, preclinical studies have demonstrated that while inhibition of AR decreases the expression of TMPRSS2, it may lead to

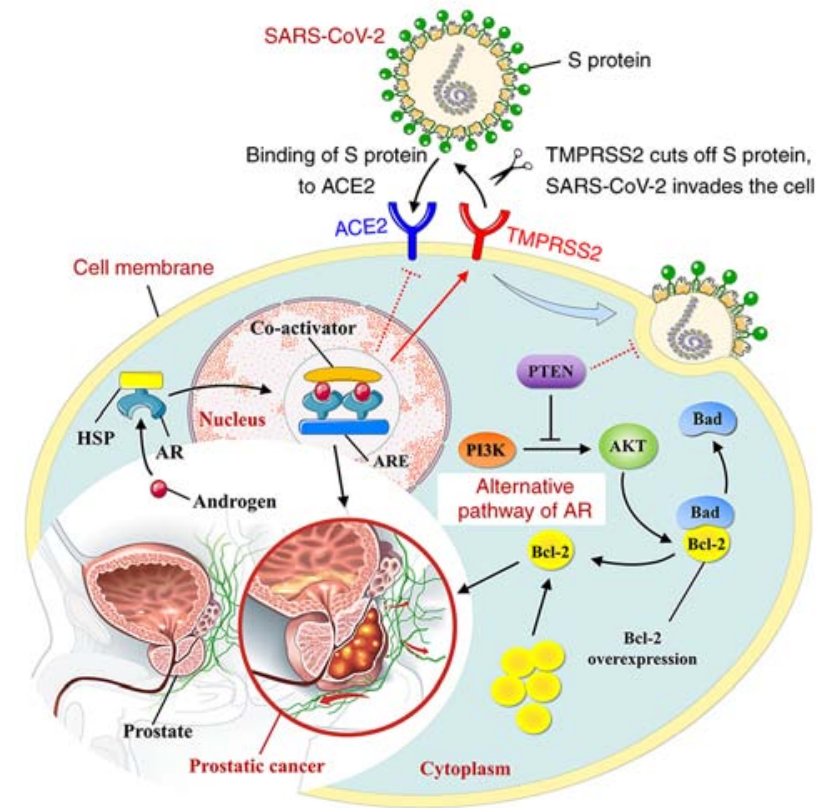

Figure 5. Association between SARS-CoV-2 infection and androgen receptor signaling. Activation of androgen receptor complex promotes the expression of TMPRSS2, while inhibiting ACE2 activities. In addition, activation of tumor suppressor gene PTEN inhibits the progression of prostatic cancer by suppressing the alternative pathway of androgen receptor, while preventing against SARS-CoV-2 infection in host cells. Dotted lines indicate mechanisms that have yet to be validated. SARS-CoV-2, Severe acute respiratory syndrome coronavirus 2; TMPRSS2, transmembrane serine protease 2 ; ACE, angiotensin-converting enzyme inhibitor; AR, androgen response; ARE, androgen response element; HSP, heat shock protein; PTEN, gene of phosphate and tension homology deleted on chromosome 10.

an upregulation in the expression of ACE2, increasing the risk of SARS-CoV-2 infection (107). Therefore, the potential negative outcome caused by inhibition of AR needs to be further evaluated.

Downregulating the expression of ACE2 using ACE inhibitors (ACEIS). It has been reported that patients with various cardiovascular diseases, diabetes or hypertension have an elevated level of ACE2, while displaying a relatively high risk of dying from COVID-19 (110). Notably, the expression level of ACE2 in kidney is higher than that in other organs; the level in kidney can be 100 times as high as that in lung (110). Thus, studies on shared molecular markers and overlapping signaling pathways between renal cell carcinoma (RCC) and COVID-19 will be of great clinical significance for the treatment of RCC patients complicated with COVID-19. Administration with ACEIs can reduce the tumor growth and metastatic potential, prolonging the survival period of patients with RCC. In addition, ACE2 inhibition leads to decreased ACE2 available for binding with the viruses (111-113), probably reducing the susceptibility of patients with RCC to SARS-CoV-2. Likewise, inhibition of ACE2 in other types of malignancies can effectively block the entry of SARS-CoV-2 into host cells. Cancer cells in general express higher levels of ACE2 compared with their adjacent normal cells and thus can be potentially more susceptible to SARS-CoV-2 infection (3). Since cancer cells have managed to evade host immune response in the first place, this may provide a better microenvironment for SARS-CoV-2 replication in 
cancer cells/tissues, which may partly explain why patients with cancer seem to be more susceptible to SARS-CoV-2 infection (87). Although ACEI-caused decline in bradykinin degradation may stimulate the growth, survival and migration of cancer cells, these effects can be finally counteracted by decreased expression of VEGFs due to ACEI-caused reduction in Ang II level and angiogenesis (110).

Strengthening anticoagulant prevention and treatment of diseases at early stage. It has been shown that the expression of tissue factor in tumor cells can promote tumor growth and angiogenesis, thereby resulting in release of coagulant particles into circulation system, which subsequently triggers thromboembolism in patients with cancer (114). Given that concomitant infection with COVID-19 and hypoxia in patients with cancer lead to a higher risk of developing a thrombotic event, anticoagulant therapy could serve as one of preventive and treatment strategies for patients with cancer and infected with COVID-19 (115). It is thought that early administration of heparin can defer the dramatic increase of inflammatory biomarkers and downregulate coagulation state. A retrospective study conducted in China investigated 449 patients with severe COVID-19, among which 272 suffered from one or more chronic underlying diseases such as hypertension and heart diseases. In that study, patients underwent the treatment with various forms of heparin and a relatively lower mortality rate was observed in patients treated with heparin (40\% vs. $64.2 \%, \mathrm{P}=0.029)$ (116). Similarly, statins with anti-inflammatory, anti-thrombotic and immunomodulatory effects may reduce the risk of cardiovascular complications and thromboembolic events in patients with COVID-19 (117). In addition, ACEI, angiotensin receptor blockers, CCR5 treatment (118-120), tyrosine kinase inhibitors (TKIs) (121-125), bevacizumab $(126,127)$, ruxolitinib $(126,128)$, carmofur $(126,129)$ and toremifene $(126,130)$ could potentially be used as cancer therapy regimens aimed at counteracting COVID-19 mechanistically (Table I).

Supplementing intestinal probiotics. Notably, SARS-CoV-2 RNAs have been detected in the feces of certain patients with COVID-19 (131). Thus, diversity of intestinal flora and the presence of intestinal probiotics may serve an important role in assessing the disease course of COVID-19 (132). Patients with cancer usually display a compromised immune function as well as general imbalance of intestinal flora, which are very likely to aggravate the clinical manifestation of COVID-19 (132). Therefore, the recovery of patients with cancer infected with SARS-CoV-2 could be promoted by the administration of effective probiotics (e.g., fructooligosaccharide (FOS), galactooligosaccharides (GOS) and various Lactobacillus strains), which are selected based on analysis of intestinal flora in these patients. Alternatively, patients with cancer can take special probiotics for improving intestinal dystrophy, enhancing immunity and preventing against SARS-CoV-2 infection. Studies on effects of SARS-CoV-2 on the intestinal ecosystem in patients with cancer will provide new ideas for preventing and controlling the viral infection of patients with declined immunity such as patients with cancer.
Regularly supplementing vitamin and micronutrients. Vitamin $\mathrm{D}$ is a fat-soluble vitamin that can be obtained from the diet, the classic role of which is to promote bone remodeling (133). Serum levels of 25-hydroxyvitamin D [25 (OH) D] have been shown to be negatively associated with a higher risk of colon, breast, prostate, stomach and other cancers (134). Vitamin D deficiency has been proved to contribute to the occurrence and progression of a number of cancers, so maintaining adequate serum vitamin D levels may be beneficial for cancer prevention and treatment (134). Recent studies have reported a significant association between the average level of vitamin D and the number of patients with COVID-19, especially the mortality rate $(133,135-137)$. Vitamin D deficiency is present in $>80 \%$ of patients with severe COVID-19 and is associated with poor prognosis $(133,136)$. Vitamin D deficiency may contribute to the exacerbation of COVID-19 through inducing thrombotic effects and immune dysregulation (136). In immune response, vitamin D-dependent antimicrobial pathways are known to respond to double-stranded RNA produced in replication processes of SARS-CoV-2 $(136,138)$. These pathways subsequently upregulated the autophagy of damaged cells, as well as levels of various antimicrobial and antiviral peptides $(136,138)$. Thus, vitamin D deficiency may predispose a host to SARS-CoV-2 infection by blocking the activation of above defense pathways and the migration of lymphocytes and macrophages (136). These findings suggest that vitamin D may protect the body from acute respiratory infections, while elderly patients with cancer and extreme vitamin $\mathrm{D}$ deficiency may be more susceptible to COVID-19. In addition to vitamin $\mathrm{D}$, adequate levels of vitamin $\mathrm{C}$ and $\mathrm{E}$ are also essential to reduce the burden of symptoms and shorten the duration of respiratory infections during the COVID-19 pandemic (137). Micronutrients such as selenium and zinc, the dietary supplements in multivitamin tablets, not only serve important roles in cancer progression and therapy, but can also increase the immune responses against viral infection $(138,139)$. It is speculated that selenium and zinc may also have a potential inhibitory effect on COVID-19 infection $(137,138)$. Thus, regular supplementation of vitamin and other micronutrients may improve severe COVID-19 symptoms and survival in elderly patients with cancer. However, it is worth noting that further research is needed to determine the effective dose of vitamin and micronutrients supplements to help patients with cancer alleviate the symptoms of COVID-19.

The COVID-19 vaccination policies for patients with cancer. At present, there are differences in the COVID-19 vaccination policy for patients with cancer. In some countries, the COVID-19 vaccine is not recommended for patients with malignant tumors, or even as a contraindication for vaccination (140). The main reason is the lack of clinical data on COVID-19 vaccine for patients with cancer, so the safety status, effectiveness and immune response after vaccination cannot be evaluated. However, recent reports show that even for patients with cancer, if there are no contraindications to the vaccine components, they may still receive COVID-19 vaccination and get sufficiently high immunogenicity (141-143). Although patients with cancer may have a delayed response to the vaccine, it may still bring some benefits, which is important for reducing the risk or severity of SARS-CoV-2 to patients with 


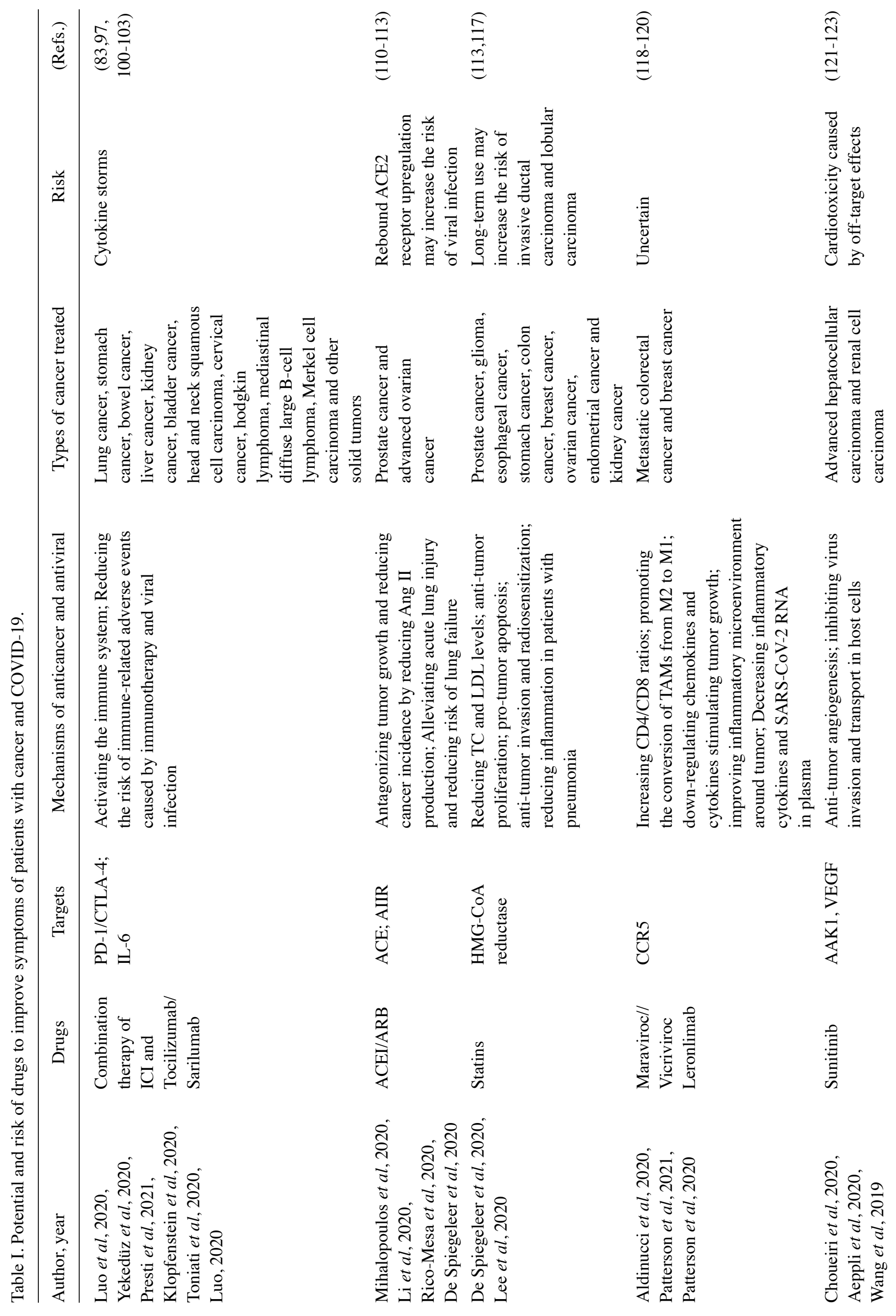




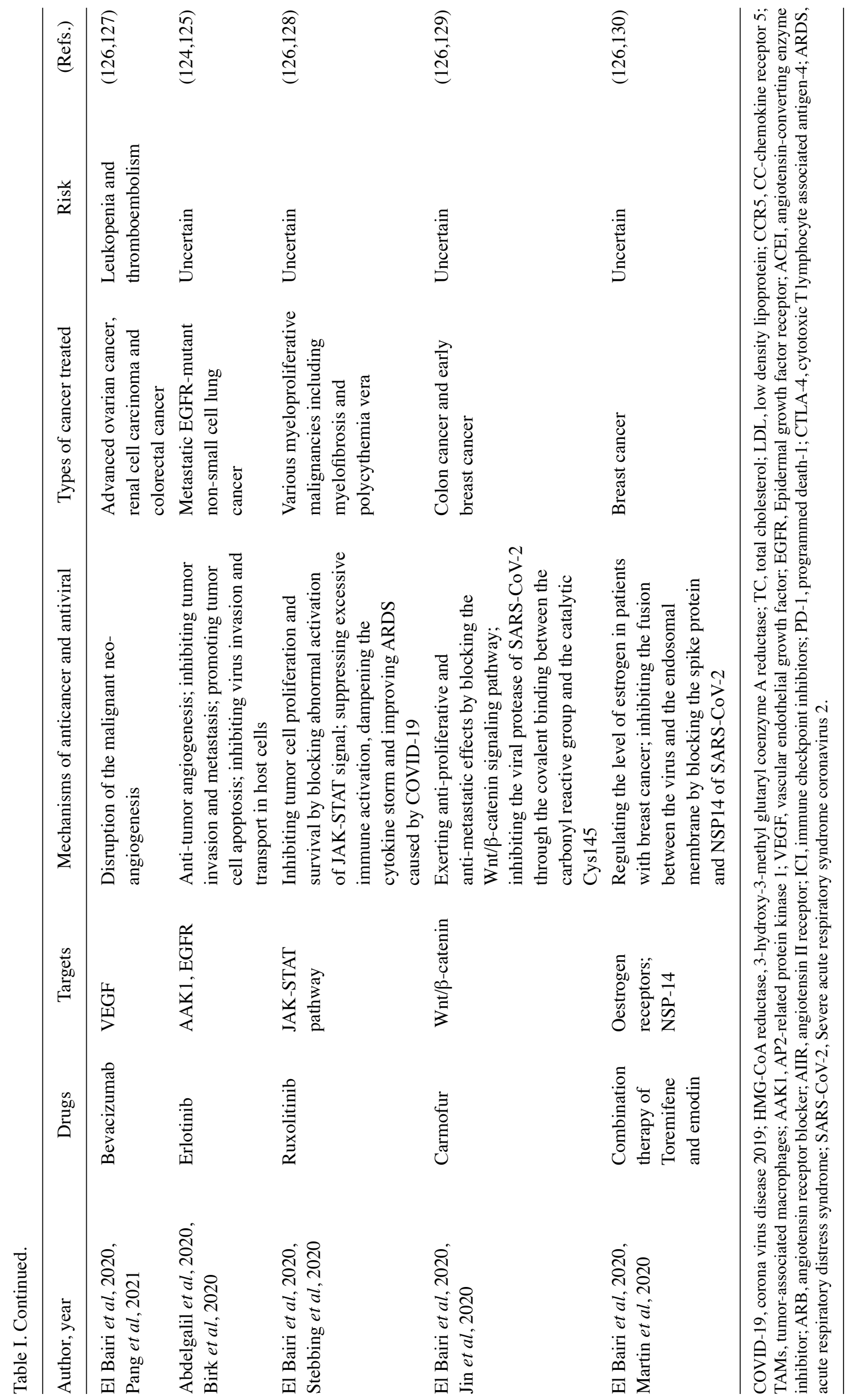




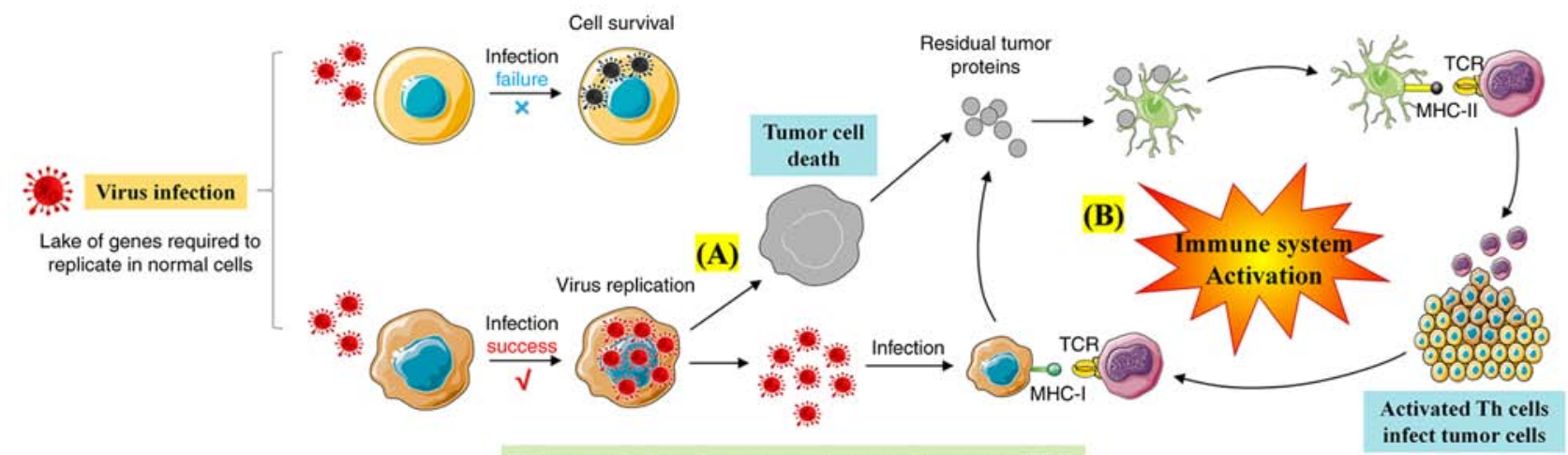

Release of virus in tumor microenvironment (TM)

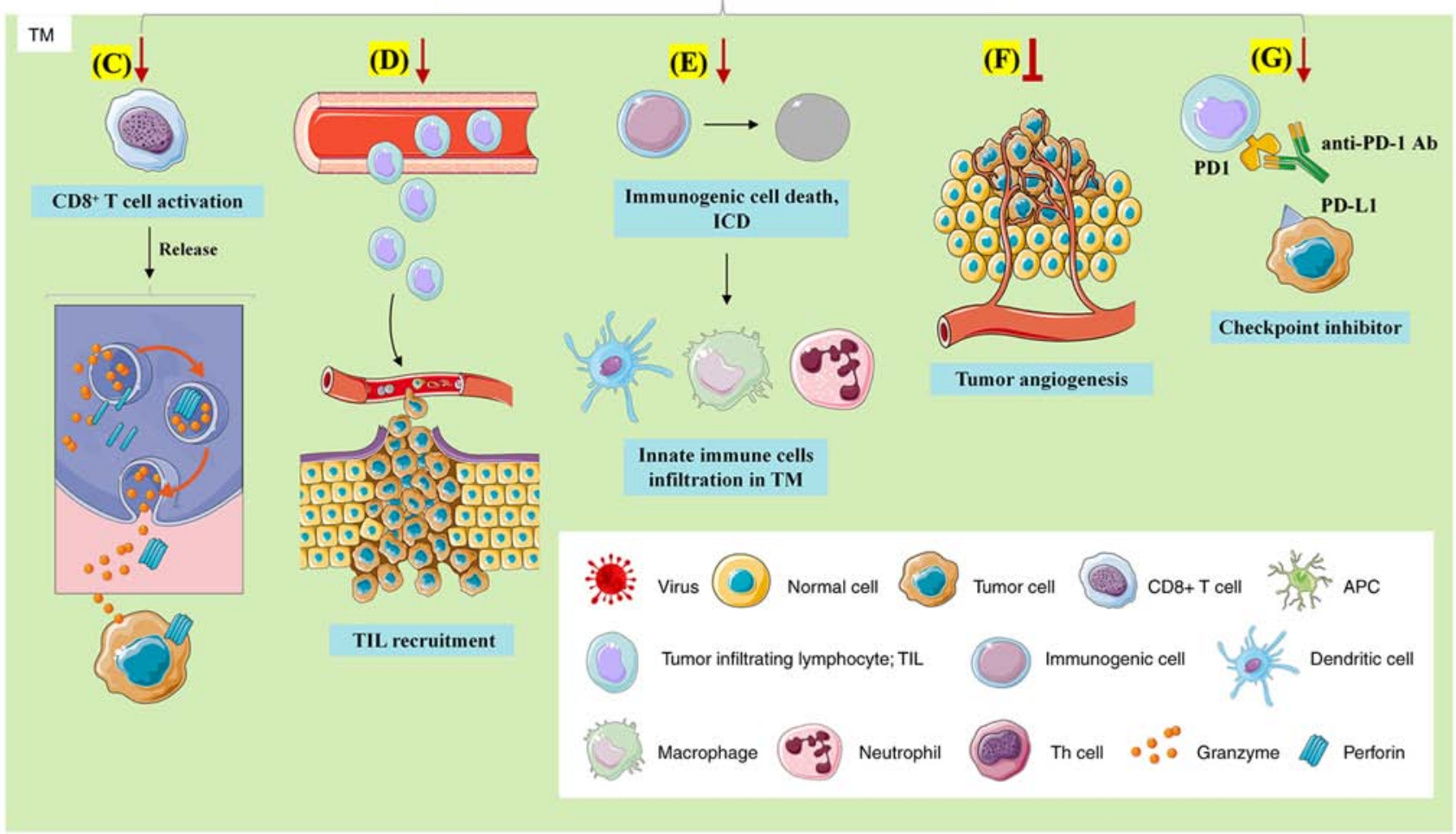

Figure 6. Anti-tumor mechanisms of oncolytic viruses. The mechanisms underlying the anti-tumor effect of oncolytic viruses involve: (A) Direct tumor lysis; (B) regulation of tumor immune microenvironment; (C) activation of CD8+ T cells; (D) TIL recruitment; (E) promoting immunogenic cell death; (F) inhibition of tumor angiogenesis; (G) enhanced anti-tumor effect of immune checkpoint inhibitors. TIL, tumor infiltrating lymphocyte.

cancer $(141,142)$. However, certain treatments for cancer, such as chemotherapy or immunotherapy, can weaken the immune system and may increase the risk of COVID-19 infection (144). Therefore, patients with early malignant tumors who have completed radical treatment and are not receiving anti-tumor therapy, can be vaccinated with COVID-19 vaccine; for patients with malignant tumors who are receiving chemotherapy, targeted therapy or immunotherapy, the vaccine should be used with caution; for patients with malignant tumors who are receiving endocrine therapy, the vaccine can be given to those in good health, while is not recommended for patients in poor health, whether or not they are receiving anti-tumor therapy $(141,145)$. In the case of breast cancer, inactivated vaccines are recommended during breast cancer rehabilitation, including endocrine therapy and HER2 targeted therapy; whereas for patients undergoing surgery, chemotherapy and PD-1 treatment, it is recommended to wait for the sufficient clinical evidence to prove the safety and effectiveness before vaccination. For patients with cancer and impaired immune function, it is recommended to vaccinate live attenuated vaccines and recombinant subunit vaccines; and it is recommended to weigh the benefit and the risk before vaccinating with adenovirus vector vaccines (142). Notably, due to the low immune function, the degree of immunity of patients with cancer after vaccination is still uncertain. Patients with cancer vaccinated should continue to follow current guidance to avoid COVID-19 infection.

\section{Oncolytic viruses and SARS-CoV-2}

Oncolytic viruses. Oncolytic viruses are a class of natural or genetically-modified viruses that are capable of self-replicating and killing cancer cells (146). After infecting cancer cells, oncolytic viruses will replicate massively in the cells and promote the lytic cell death during the replicative process (Fig. 6) (146-149). At present, the latest clinical regimen for 


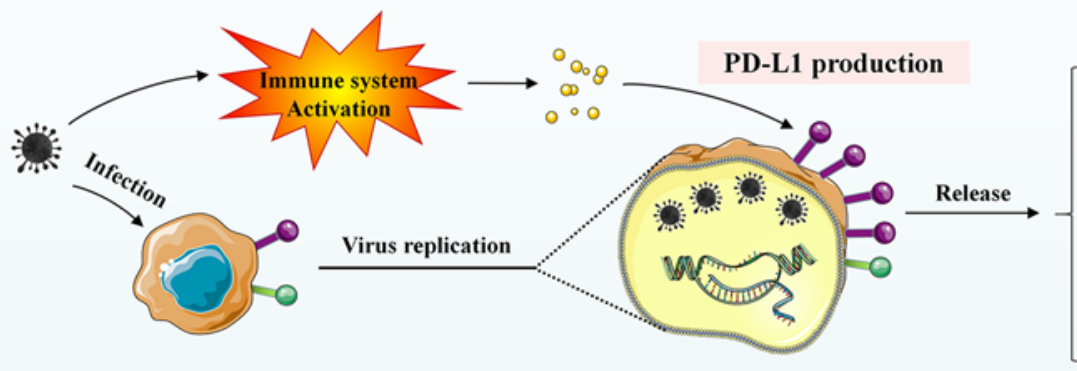

A

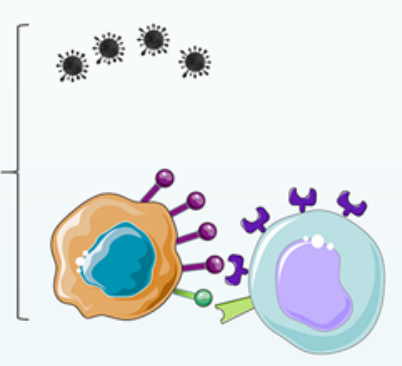

Successful binding of PD1 and PD-L1

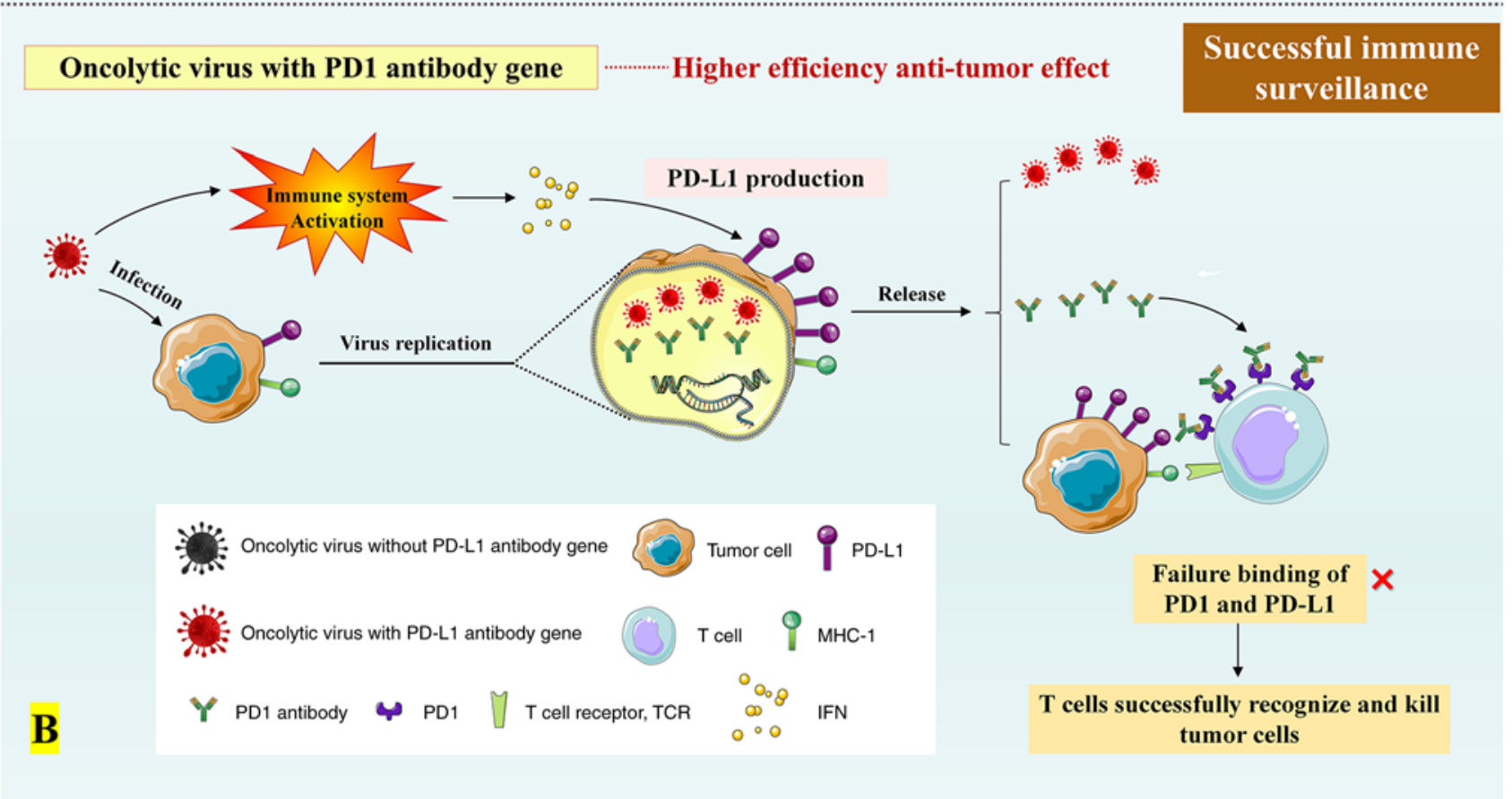

Figure 7. Effect of integrated PD1 antibody gene on anti-tumor function of oncolytic viruses. (A) While infecting tumors, oncolytic viruses may also promote the expression of PD-L1 on the tumor surface by inducing the release of IFN. The combination of PD-L1 with PD-1 can aid tumors to escape T cell immunity. (B) Recombinant oncolytic viruses with PD-1 antibody gene can produce PD-1 antibodies while replicating in the cancer cells. In this case, binding of PD-1 antibody to PD-1 leads to a competitive inhibition in binding of PD-1 to PD-L1 in the surface of cancer cells, thus suppressing the immune evasion of tumor cells.

combined therapy of oncolytic viruses involves a combination with PD-1/PD-L1 antibodies, providing effective and individualized tumor specific oncolytic immunotherapy to patients with cancer who are resistant to PD-1/PD-L1 blockade therapy $(149,150)$. Notably, it has been shown that oncolytic viruses can trigger antiviral response of the immune system to increase the level of interferons in the tumor environment, thereby promoting PD-L1 production for the immune evasion (Fig. 7) (149).

Does SARS-CoV-2 display potential oncolytic characteristics? It has been shown that ACE2 serves as a key target for SARS-CoV-2 infection of host cells $(3,110)$. As NK cells massively express ACE2, they are easily infected by SARS-CoV-2, resulting in a decline in cell numbers as well as loss of immune function (151). Certain RNA viruses causing acute pulmonary infection have been found to promote apoptosis in NK cells (12). Notably, elevated levels of IL-6 and IL-10 caused by SARS-CoV-2 infection lead to a marked decrease in the cytotoxicity of NK cells, while SARS-CoV-2-induced release of IL-2 and TNF- $\alpha$ recruits NK and T cells into the tumor tissue (12). Based on the above observations, it is hypothesized that excessive production of proinflammatory cytokines during COVID-19 infection may serve a pivotal role in lymph node clearance. The depletion and inactivation of NK cells could serve as a therapeutic regimen for NK lymphoma patients who are resistant to conventional chemotherapy and improve the signs and clinical symptoms of the patients with cancer. In addition, the viral copy number of EBV-DNA, a sensitive biomarker of NK/T cell lymphoma, has been shown to be markedly declined during the course of COVID-19 (12). In addition, serum copy number of EBV-DNA, cell number of NK cell clones and recurrence rate of lymphoma in patients with NK lymphoma are increased 
after the subsiding of SARS-CoV-2 infection (12), indicating that COVID-19 infection can defer the tumor progression of NK lymphoma patients. The binding between SARS-CoV-2 and the respective receptors such as ACE2 in NK cells may determine its targeting of oncolytic adenoviruses. All these observations suggest that while SARS-CoV-2-induced immune response exerts an anti-tumor effect to a certain extent, SARS-CoV-2 displays potential oncolytic characteristics for lymphoma patients.

In addition, recent studies have suggested that SARS-CoV-2 infection may protect against Hodgkin's lymphoma by eliciting an anti-tumor immune response (149). Shortly after having been diagnosed with advanced Hodgkin's lymphoma, a 61-year-old man with severe kidney disease who was on long-term dialysis had been confirmed with COVID-19 infection (149). After 11 days hospitalization, he was discharged and returned home for rehabilitation. No corticosteroids or immunochemotherapy was received during his hospitalization and rehabilitation. However, four months after being discharged from the hospital, CT reviews of the patient demonstrated reduced palpable lymphadenopathy, interim PET/CT scans displayed the extensive retrogression of lymphadenopathy and an overall reduction of metabolic absorption and levels of tumor-related biomarkers decreased by $>90 \%(149,152)$. This medical report suggests that possible mechanisms of oncolytic responses of SARS-CoV-2 may cover cross reactions between pathogen-specific T-cells and tumor antigens and the activation of natural killer cells through inflammatory cytokines generated during response to the infection of SARS-CoV-2. In addition, the majority of tumor patients suffer from nephropathy, diabetes and other complications and oncolytic virus therapy can partially offset the hepatorenal toxicity and metabolic disorders caused by chemotherapy and immunosuppressive agents. At present, studies provide evidence that combination therapy with oncolytic vaccine and toxoid can help initiate anti-tumor immune response of the immune system via CD4+ memory T cells. Therefore, if oncolytic characteristics of SARS-CoV-2 could be combined with the memory of $\mathrm{T}$ cells by genetic modification to recall the immunity of known antigens to coronavirus, this scenario may provide a new approach for the genetic modification of oncolytic viruses.

\section{Conclusion}

SARS-CoV-2 may affect tumor progression through multiple mechanisms, including glycolysis, translational modification, nucleic acid synthesis, lipid metabolism and transcriptional splicing. Patients with cancer complicated with COVID-19 have a greater chance of developing a severe and critical illness as well as a poorer prognosis. Given that immunopotentiation therapies such as ICI and CAR-T used for tumor treatment could aggravate inflammatory symptoms of patients with COVID-19, targeted therapy or immunotherapy should be postponed accordingly based on risk of disease progression. While either chemotherapeutic drugs with low risk of immunosuppression or short fractionated radiotherapy can be preferentially applied to non-metastatic patients with cancer or those with cancer at early stage; administration with high selective inhibitors targeting for TMPRSS2 or ACE2 might be a feasible regimen for protecting advanced patients with cancer against SARS-CoV-2 infection. In addition, regular supplementation of vitamin and other micronutrients may improve severe COVID-19 symptoms and survival in elderly patients with cancer. The correlation of dynamic changes of COVID-19 antibody, nucleic acids, tumor metabolism pathway switch and levels of tumor-related cytokines with the prognosis during the disease course of patients with cancer is worthy of further study. Given SARS-CoV-2-activated anti-tumor immune response and its toxic inhibitory effect on NK cells, SARS-CoV-2 may possess potential oncolytic characteristics in lymphoma patients. Therefore, genetic modification of SARS-CoV-2 and in-depth studies of immune-stimulating mechanism may provide more new directions for oncolytic virotherapy.

\section{Acknowledgements}

Not applicable.

Funding

No funding was received.

\section{Availability of data and materials}

Data sharing is not applicable to this article, as no data sets were generated or analyzed during the current study.

\section{Authors' contributions}

YSL conceived the study and wrote the manuscript. HCR summarized and analyzed the data and produced graphs. JHC contributed to the critical reading and correction of the manuscript. Data authentication is not applicable. All authors have read and approved the final manuscript.

\section{Ethics approval and consent to participate}

Not applicable.

\section{Patient consent for publication}

Not applicable.

\section{Competing interests}

The authors declare that they have no competing interests.

\section{References}

1. Hartenian E, Nandakumar D, Lari A, Ly M, Tucker JM and Glaunsinger BA: The molecular virology of coronaviruses. J Biol Chem 295: 12910-12934, 2020.

2. Mortaz E, Tabarsi P, Varahram M, Folkerts G and Adcock IM: The immune response and immunopathology of COVID-19. Front Immunol 11: 2037, 2020.

3. Tan HW, Xu YM and Lau ATY: Angiotensin-converting enzyme 2: The old door for new severe acute respiratory syndrome coronavirus 2 infection. Rev Med Virol 30: e2122, 2020.

4. Ye ZW, Yuan S, Yuen KS, Fung SY, Chan CP and Jin DY: Zoonotic origins of human coronaviruses. Int J Biol Sci 16: 1686-1697, 2020 
5. Chang L, Yan Y and Wang L: Coronavirus disease 2019 Coronaviruses and blood safety. Transfus Med Rev 34: 75-80, 2020.

6. Yi C, Sun X, Ye J, Ding L, Liu M, Yang Z, Lu X, Zhang Y, $\mathrm{Ma} \mathrm{L}, \mathrm{Gu}$ W, et al: Key residues of the receptor binding motif in the spike protein of SARS-CoV-2 that interact with ACE2 and neutralizing antibodies. Cell Mol Immunol 17: 621-630, 2020.

7. Yuan M, Wu NC, Zhu X, Lee CD, So RTY, Lv H, Mok CKP and Wilson IA: A highly conserved cryptic epitope in the receptor binding domains of SARS-CoV-2 and SARS-CoV. Science 368 630-633, 2020

8. Jiang S, Hillyer C and Du L: Neutralizing antibodies against SARS-CoV-2 and other human coronaviruses. Trends Immunol 41: 355-359, 2020.

9. van Dam PA, Huizing M, Mestach G, Dierckxsens S, Tjalma W, Trinh XB, Papadimitriou K, Altintas S, Vermorken J, Vulsteke C, et al: SARS-CoV-2 and cancer: Are they really partners in crime? Cancer Treat Rev 89: 102068, 2020.

10. Garrone O, Denaro N, Ruatta F, Vanella P, Granetto C Vandone AM, Occelli M, Cauchi C, Ricci V, Fea E, et al: Treating patients with cancer amidst the COVID-19 pandemic: Experience of a regional hospital in the Piedmont region in northern Italy. Tumori 106: 427-431, 2020.

11. Bojkova D, Klann K, Koch B, Widera M, Krause D, Ciesek S, Cinatl J and Münch C: Proteomics of SARS-CoV-2-infected host cells reveals therapy targets. Nature 583: 469-472, 2020.

12. Pasin F, Mascalchi Calveri M, Calabrese A, Pizzarelli G, Bongiovanni I, Andreoli M, Cattaneo C and Rignanese G Oncolytic effect of SARS-CoV2 in a patient with NK lymphoma. Acta Biomed 91: e2020047, 2020.

13. Akram N, Imran M, Noreen M, Ahmed F, Atif M, Fatima Z and Bilal Waqar A: Oncogenic role of tumor viruses in humans. Viral Immunol 30: 20-27, 2017.

14. White MK, Pagano JS and Khalili K: Viruses and human cancers: A long road of discovery of molecular paradigms. Clin Microbiol Rev 27: 463-481, 2014.

15. Kuss-Duerkop SK, Westrich JA and Pyeon D: DNA tumor virus regulation of host DNA methylation and its implications for immune evasion and oncogenesis. Viruses 10: 82, 2018.

16. Liu S, Kaddis Maldonado R, Rye-McCurdy T, Binkley C, Bah A Chen EC, Rice BL, Parent LJ and Musier-Forsyth K: Rous sarcoma virus genomic RNA dimerization capability in vitro is not a prerequisite for viral infectivity. Viruses 12: 568, 2020.

17. Simatou A, Simatos G, Goulielmaki M, Spandidos DA, Baliou S and Zoumpourlis V: Historical retrospective of the SRC oncogene and new perspectives (review). Mol Clin Oncol 13: 21, 2020

18. Dupin N and Deleuze J: Kaposi sarcoma and HHV-8: A model of cutaneous cancer in immunosuppressed patients. Rev Prat 64: 311-316, 2014 (In French).

19. Stern J, Miller G, Li X and Saxena D: Virome and bacteriome: Two sides of the same coin. Curr Opin Virol 37: 37-43, 2019.

20. Etta EM, Alayande DP, Mavhandu-Ramarumo LG, Gachara G and Bessong PO: HHV-8 seroprevalence and genotype distribution in Africa, 1998-2017: A systematic review. Viruses 10: 458, 2018

21. Rusan M, Li YY and Hammerman PS: Genomic landscape of human papillomavirus-associated cancers. Clin Cancer Res 21: 2009-2019, 2015.

22. Ojesina AI, Lichtenstein L, Freeman SS, Pedamallu CS, Imaz-Rosshandler I, Pugh TJ, Cherniack AD, Ambrogio L, Cibulskis K, Bertelsen B, et al: Landscape of genomic alterations in cervical carcinomas. Nature 506: 371-375, 2014.

23. Parfenov M, Pedamallu CS, Gehlenborg N, Freeman SS Danilova L, Bristow CA, Lee S, Hadjipanayis AG, Ivanova EV, Wilkerson MD, et al: Characterization of HPV and host genome interactions in primary head and neck cancers. Proc Natl Acad Sci USA 111: 15544-15549, 2014.

24. Lei J, Ploner A, Elfström KM, Wang J, Roth A, Fang F, Sundström K, Dillner J and Sparén P: HPV vaccination and the risk of invasive cervical cancer. N Engl J Med 383: 1340-1348, 2020.

25. Sadri Nahand J, Moghoofei M, Salmaninejad A, Bahmanpour Z, Karimzadeh M, Nasiri M, Mirzaei HR, Pourhanifeh MH, Bokharaei-Salim F, Mirzaei H and Hamblin MR: Pathogenic role of exosomes and microRNAs in HPV-mediated inflammation and cervical cancer: A review. Int J Cancer 146: 305-320, 2020 .

26. Chen J, Kendrick S and Qin Z: Mechanistic insights into chemoresistance mediated by oncogenic viruses in lymphomas. Viruses 11: 1161, 2019.
27. Paradowska E, Jabłońska A, Studzińska M, Wilczyński M and Wilczyński JR: Detection and genotyping of CMV and HPV in tumors and fallopian tubes from epithelial ovarian cancer patients. Sci Rep 9: 19935, 2019.

28. Li A, Wu J, Zhai A, Qian J, Wang X, Qaria MA, Zhang Q, Li Y, Fang Y, Kao W, et al: HBV triggers APOBEC2 expression through miR-122 regulation and affects the proliferation of liver cancer cells. Int J Oncol 55: 1137-1148, 2019.

29. Levrero M and Zucman-Rossi J: Mechanisms of HBV-induced hepatocellular carcinoma. J Hepatol 64 (Suppl 1): S84-S101, 2016.

30. Zapatka M, Borozan I, Brewer DS, Iskar M, Grundhoff A, Alawi M, Desai N, Sültmann H, Moch H; PCAWG Pathogens, et al: The landscape of viral associations in human cancers. Nat Genet 52: 320-330, 2020.

31. Peng RJ, Han BW, Cai QQ, Zuo XY, Xia T, Chen JR, Feng LN, Lim JQ, Chen SW, Zeng MS, et al: Genomic and transcriptomic landscapes of Epstein-Barr virus in extranodal natural killer T-cell lymphoma. Leukemia 33: 1451-1462, 2019.

32. De Re V, Caggiari L, De Zorzi M, Fanotto V, Miolo G, Puglisi F, Cannizzaro R, Canzonieri V, Steffan A, Farruggia P, et al: Epstein-Barr virus BART microRNAs in EBV-associated Hodgkin lymphoma and gastric cancer. Infect Agents Cancer 15 : 42, 2020.

33. Camargo MC, Kim KM, Matsuo K, Torres J, Liao LM, Morgan D, Michel A, Waterboer T, Song M, Gulley ML, et al: Circulating antibodies against Epstein-Barr virus (EBV) and p53 in EBV-positive and -negative gastric cancer. Cancer Epidemiol Biomarkers Prev 29: 414-419, 2020.

34. Fitzsimmons L, Cartlidge R, Chang C, Sejic N, Galbraith LCA, Suraweera CD, Croom-Carter D, Dewson G, Tierney RJ, Bell AI, et al: EBV BCL-2 homologue BHRF1 drives chemoresistance and lymphomagenesis by inhibiting multiple cellular pro-apoptotic proteins. Cell Death Differ 27: 1554-1568, 2020.

35. Fukayama M, Abe H, Kunita A, Shinozaki-Ushiku A, Matsusaka K, Ushiku T and Kaneda A: Thirty years of Epstein-Barr virus-associated gastric carcinoma. Virchows Arch 476: 353-365, 2020.

36. Rahman M, Dastmalchi F, Karachi A and Mitchell D: The role of $\mathrm{CMV}$ in glioblastoma and implications for immunotherapeutic strategies. Oncoimmunology 8: e1514921, 2018.

37. Chang Z, Wang Y, Zhou X and Long JE: STAT3 roles in viral infection: Antiviral or proviral? Future Virol 13: 557-574, 2018.

38. Wilski NA and Snyder CM: From vaccine vector to oncomodulation: Understanding the complex interplay between CMV and cancer. Vaccines (Basel) 7: 62, 2019.

39. Bayurova E, Jansons J, Skrastina D, Smirnova O, Mezale D, Kostyusheva A, Kostyushev D, Petkov S, Podschwadt P, Valuev-Elliston V, et al: HIV-1 reverse transcriptase promotes tumor growth and metastasis formation via ROS-dependent upregulation of twist. Oxid Med Cell Longev 2019: 6016278, 2019.

40. Purushothaman P, Uppal T, Sarkar R and Verma SC: $\mathrm{KSHV}$-mediated angiogenesis in tumor progression. Viruses 8: 198, 2016.

41. Dupin N: Update on oncogenesis and therapy for Kaposi sarcoma. Curr Opin Oncol 32: 122-128, 2020.

42. Markazi A, Bracci PM, McGrath M and Gao SJ: Pseudomonas aeruginosa stimulates inflammation and enhances Kaposi's sarcoma herpesvirus-induced cell proliferation and cellular transformation through both lipopolysaccharide and flagellin. mBio 11: e02843-20, 2020.

43. Yasunaga JI: Strategies of human T-cell leukemia virus type 1 for persistent infection: Implications for leukemogenesis of adult T-cell leukemia-lymphoma. Front Microbiol 11: 979, 2020.

44. Higuchi Y, Yasunaga JI, Mitagami Y, Tsukamoto $\mathrm{H}$, Nakashima K, Ohshima K and Matsuoka M: HTLV-1 induces $\mathrm{T}$ cell malignancy and inflammation by viral antisense factor-mediated modulation of the cytokine signaling. Proc Natl Acad Sci USA 117: 13740-13749, 2020.

45. Benkheil M, Paeshuyse J, Neyts J, Van Haele M, Roskams T and Liekens S: HCV-induced EGFR-ERK signaling promotes a pro-inflammatory and pro-angiogenic signature contributing to liver cancer pathogenesis. Biochem Pharmacol 155: 305-315, 2018.

46. El-Bendary M, Nour D, Arafa M and Neamatallah M: Methylation of tumour suppressor genes RUNX3, RASSF1A and E-Cadherin in HCV-related liver cirrhosis and hepatocellular carcinoma. Br J Biomed Sci 77: 35-40, 2020. 
47. Huang P, Wang CH, Zhuo LY, Xia XS, Yang S, Zhang JW, Fan HZ, Wu JJ, Yu R, Yue M and Zhang Y: Polymorphisms rs763110 in FASL is linked to hepatitis $C$ virus infection among high-risk populations. Br J Biomed Sci 77: 112-117, 2020.

48. Defrancesco I, Zerbi C, Rattotti S, Merli M, Bruno R, Paulli M and Arcaini L: HCV infection and non-Hodgkin lymphomas: An evolving story. Clin Exp Med 20: 321-328, 2020

49. Elgui de Oliveira D: DNA viruses in human cancer: An integrated overview on fundamental mechanisms of viral carcinogenesis. Cancer Lett 247: 182-196, 2007.

50. Fujimuro M, Wu FY, ApRhys C, Kajumbula H, Young DB, Hayward GS and Hayward SD: A novel viral mechanism for dysregulation of beta-catenin in Kaposi's sarcoma-associated herpesvirus latency. Nat Med 9: 300-306, 2003.

51. Buchkovich NJ, Yu Y, Zampieri CA and Alwine JC: The TORrid affairs of viruses: Effects of mammalian DNA viruses on the PI3K-Akt-mTOR signalling pathway. Nat Rev Microbiol 6 : 266-275, 2008

52. Gaglia MM and Munger K: More than just oncogenes: Mechanisms of tumorigenesis by human viruses. Curr Opin Virol 32: 48-59, 2018

53. Imamichi $H$, Smith $M$, Adelsberger JW, Izumi T, Scrimieri $F$, Sherman BT, Rehm CA, Imamichi T, Pau A, Catalfamo M, et al: Defective HIV-1 proviruses produce viral proteins. Proc Natl Acad Sci USA 117: 3704-3710, 2020.

54. Takahashi M, Kawai K and Asai N: Roles of the RET protooncogene in cancer and development. JMA J 3: 175-181, 2020.

55. Wang H, Boussouar A, Mazelin L, Tauszig-Delamasure S, Sun Y, Goldschneider D, Paradisi A and Mehlen P: The proto-oncogene c-Kit inhibits tumor growth by behaving as a dependence receptor. Mol Cell 72: 413-425.e5, 2018.

56. Chen S, Li F, Xu D, Hou K, Fang W and Li Y: The function of RAS mutation in cancer and advances in its drug research. Curr Pharm Des 25: 1105-1114, 2019.

57. Terrell EM, Durrant DE, Ritt DA, Sealover NE, Sheffels E, Spencer-Smith R, Esposito D, Zhou Y, Hancock JF, Kortum RL and Morrison DK: Distinct binding preferences between Ras and Raf family members and the impact on oncogenic Ras signaling. Mol Cell 76: 872-884.e5, 2019

58. Zhang Y, Wu D and Wang D: Long non-coding RNA ARAP1-AS1 promotes tumorigenesis and metastasis through facilitating proto-oncogene c-Myc translation via dissociating $\mathrm{PSF} / \mathrm{PTB}$ dimer in cervical cancer. Cancer Med 9: 1855-1866, 2020

59. Trigo J, Subbiah V, Besse B, Moreno V, López R, Sala MA, Peters S, Ponce S, Fernández C, Alfaro V, et al: Lurbinectedin as second-line treatment for patients with small-cell lung cancer: A single-arm, open-label, phase 2 basket trial. Lancet Oncol 21: $645-654,2020$

60. Adoue V and Joffre O: Endogenous retroviruses: Friend or foe of the immune system? Med Sci (Paris) 36: 253-260, 2020 (In French).

61. Giannuzzi D and Aresu L: A first NGS investigation suggests no association between viruses and canine cancers. Front Vet Sci 7: $365,2020$.

62. He J, Tao H, Yan Y, Huang SY and Xiao Y: Molecular mechanism of evolution and human infection with SARS-CoV-2. Viruses 12 : $428,2020$.

63. Wang IH, Burckhardt CJ, Yakimovich A and Greber UF: Imaging, tracking and computational analyses of virus entry and egress with the cytoskeleton. Viruses 10: 166, 2018.

64. McLaughlin-Drubin ME, Crum CP and Münger K: Human papillomavirus E7 oncoprotein induces KDM6A and KDM6B histone demethylase expression and causes epigenetic reprogramming. Proc Natl Acad Sci USA 108: 2130-2135, 2011.

65. Burgers WA, Blanchon L, Pradhan S, de Launoit Y, Kouzarides T and Fuks F: Viral oncoproteins target the DNA methyltransferases. Oncogene 26: 1650-1655, 2007.

66. Avanzi S, Alvisi G and Ripalti A: How virus persistence can initiate the tumorigenesis process. World J Virol 2: 102-109, 2013.

67. Addeo A and Friedlaender A: Cancer and COVID-19: Unmasking their ties. Cancer Treat Rev 88: 102041, 2020.

68. Lauer SA, Grantz KH, Bi Q, Jones FK, Zheng Q, Meredith HR, Azman AS, Reich NG and Lessler J: The incubation period of coronavirus disease 2019 (COVID-19) from publicly reported confirmed cases: Estimation and application. Ann Intern Med 172: 577-582, 2020.

69. Tang S, Mao Y, Jones RM, Tan Q, Ji JS, Li N, Shen J, Lv Y, Pan L, Ding P, et al: Aerosol transmission of SARS-CoV-2? Evidence, prevention and control. Environ Int 144: 106039, 2020.
70. van Doremalen N, Bushmaker T, Morris DH, Holbrook MG Gamble A, Williamson BN, Tamin A, Harcourt JL, Thornburg NJ, Gerber SI, et al: Aerosol and surface stability of SARS-CoV-2 as compared with SARS-CoV-1. N Engl J Med 382: 1564-1567, 2020.

71. Smither SJ, Eastaugh LS, Findlay JS and Lever MS: Experimental aerosol survival of SARS-CoV-2 in artificial saliva and tissue culture media at medium and high humidity. Emerg Microbes Infect 9: 1415-1417, 2020

72. Bouhaddou M,Memon D, Meyer B, White KM, Rezelj VV, Correa Marrero M, Polacco BJ, Melnyk JE, Ulferts S, Kaake RM, et al: The global phosphorylation landscape of SARS-CoV-2 infection. Cell 182: 685-712.e19, 2020.

73. Kim JM, Kim HM, Lee EJ, Jo HJ, Yoon Y, Lee NJ, Son J, Lee YJ, Kim MS, Lee YP, et al: Detection and isolation of SARS-CoV-2 in serum, urine, and stool specimens of COVID-19 patients from the Republic of Korea. Osong Public Health Res Perspect 11: 112-117, 2020.

74. Elfiky AA: Ribavirin, remdesivir, sofosbuvir, galidesivir, and tenofovir against SARS-CoV-2 RNA dependent RNA polymerase (RdRp): A molecular docking study. Life Sci 253: 117592, 2020.

75. Icard P, Lincet H, Wu Z, Coquerel A, Forgez P, Alifano M and Fournel L: The key role of Warburg effect in SARS-CoV-2 replication and associated inflammatory response. Biochimie 180: 169-177, 2021.

76. Codo AC, Davanzo GG, Monteiro LB, de Souza GF, Muraro SP, Virgilio-da-Silva JV, Prodonoff JS, Carregari VC, de Biagi Junior CAO, Crunfli F, et al: Elevated glucose levels favor SARS-CoV-2 infection and monocyte response through a HIF-1 $\alpha /$ glycolysis-dependent axis. Cell Metab 32: 498-499, 2020.

77. Raymond E, Thieblemont C, Alran S and Faivre S: Impact of the COVID-19 outbreak on the management of patients with cancer. Target Oncol 15: 249-259, 2020.

78. Robilotti EV, Babady NE, Mead PA, Rolling T, Perez-Johnston R, Bernardes M, Bogler Y, Caldararo M, Figueroa CJ, Glickman MS, et al: Determinants of COVID-19 disease severity in patients with cancer. Nat Med 26: 1218-1223, 2020.

79. Lewis WD, Lilly S and Jones KL: Lymphoma: Diagnosis and treatment. Am Fam Physician 101: 34-41, 2020.

80. Arshad S, Kilgore P, Chaudhry ZS, Jacobsen G, Wang DD, Huitsing K, Brar I, Alangaden GJ, Ramesh MS, McKinnon JE, et al: Treatment with hydroxychloroquine, azithromycin, and combination in patients hospitalized with COVID-19. Int J Infect Dis 97: 396-403, 2020.

81. Johnson KM, Belfer JJ, Peterson GR, Boelkins MR and Dumkow LE: Managing COVID-19 in renal transplant recipients: A review of recent literature and case supporting corticosteroidsparing immunosuppression. Pharmacotherapy 40: 517-524, 2020.

82. Singh AK, Majumdar S, Singh R and Misra A: Role of corticosteroid in the management of COVID-19: A systemic review and a Clinician's perspective. Diabetes Metab Syndr 14; 971-978, 2020.

83. Luo P, Liu Y, Qiu L, Liu X, Liu D and Li J: Tocilizumab treatment in COVID-19: A single center experience. J Med Virol 92: 814-818, 2020

84. Wooding DJ and Bach H: Treatment of COVID-19 with convalescent plasma: Lessons from past coronavirus outbreaks. Clin Microbiol Infect 26: 1436-1446, 2020.

85. Dai M, Liu D, Liu M, Zhou F, Li G, Chen Z, Zhang Z, You H, Wu M, Zheng Q, et al: Patients with cancer appear more vulnerable to SARS-CoV-2: A multicenter study during the COVID-19 outbreak. Cancer Discov 10: 783-791, 2020.

86. Li D, Liu C, Liu J, Hu J, Yang Y and Zhou Y: Analysis of risk factors for 24 patients with COVID-19 developing from moderate to severe condition. Front Cell Infect Microbiol 10: 548582, 2020.

87. Li X, Xu S, Yu M, Wang K, Tao Y, Zhou Y, Shi J, Zhou M, Wu B, Yang Z, et al: Risk factors for severity and mortality in adult COVID-19 inpatients in Wuhan. J Allergy Clin Immunol 146: $110-118,2020$.

88. Turnquist C, Ryan BM, Horikawa I, Harris BT and Harris CC: Cytokine storms in cancer and COVID-19. Cancer Cell 38: 598-601, 2020.

89. Gosain R, Abdou Y, Singh A, Rana N, Puzanov I and Ernstoff MS: COVID-19 and cancer: A comprehensive review. Curr Oncol Rep 22: 53, 2020

90. Tian Y, Qiu X, Wang C, Zhao J, Jiang X, Niu W, Huang J and Zhang F: Cancer associates with risk and severe events of COVID-19: A systematic review and meta-analysis. Int J Cancer 148: 363-374, 2021 
91. Yang K, Sheng Y, Huang C, Jin Y, Xiong N, Jiang K, Lu H, Liu J, Yang J, Dong Y, et al: Clinical characteristics, outcomes, and risk factors for mortality in patients with cancer and COVID-19 in Hubei, China: A multicentre, retrospective, cohort study. Lancet Oncol 21: 904-913, 2020.

92.Pinato DJ, Zambelli A, Aguilar-Company J, Bower M, Sng C, Salazar R, Bertuzzi A, Brunet J, Mesia R, Segui E, et al: Clinical portrait of the SARS-CoV-2 epidemic in European cancer patients. Cancer Discov 10: 1465-1474. Jul 31, 2020. (Epub ahead of print). doi: 10.1158/2159-8290.CD-20-0773

93. Jindal V, Sahu KK, Gaikazian S, Siddiqui AD and Jaiyesimi I: Cancer treatment during COVID-19 pandemic. Med Oncol 37: 58, 2020.

94. Moris D, Tsilimigras DI and Schizas D: Cancer and COVID-19. Lancet 396: 1066, 2020.

95. Arnaldez FI, O'Day SJ, Drake CG, Fox BA, Fu B, Urba WJ, Montesarchio V, Weber JS, Wei H, Wigginton JM and Ascierto PA The society for immunotherapy of cancer perspective on regulation of interleukin-6 signaling in COVID-19-related systemic inflammatory response. J Immunother Cancer 8: e000930, 2020.

96.Zhang C, Rong HM, Li T, Zhai K and Tong ZH: PD-1 deficiency promotes macrophage activation and T-helper cell type 1/T-helper cell type 17 response in pneumocystis pneumonia. Am J Respir Cell Mol Biol 62: 767-782, 2020.

97. Yekedüz E, Dursun B, Aydın GC, Yazgan SC, Öztürk HH, Azap A, Utkan G and Ürün Y: Clinical course of COVID-19 infection in elderly patient with melanoma on nivolumab J Oncol Pharm Pract 26: 1289-1294, 2020.

98. Dumoulin DW, Gietema HA, Paats MS, Hendriks LEL and Cornelissen R: Differentiation of COVID-19 pneumonitis and ICI induced pneumonitis. Front Oncol 10: 577696, 2020.

99. Sullivan RJ, Johnson DB, Rini BI, Neilan TG, Lovly CM, Moslehi JJ and Reynolds KL: COVID-19 and immune checkpoint inhibitors: Initial considerations. J Immunother Cancer 8: $\mathrm{e} 000933,2020$

100. Presti M, Westergaard MCW, Draghi A, Chamberlain CA, Gokuldass A, Svane IM and Donia M: The effects of targeted immune-regulatory strategies on tumor-specific T-cell responses in vitro. Cancer Immunol Immunother 70: 1771-1776, 2021.

101. Klopfenstein T, Zayet S, Lohse A, Balblanc JC, Badie J, Royer PY, Toko L, Mezher C, Kadiane-Oussou NJ, Bossert M, et al: Tocilizumab therapy reduced intensive care unit admissions and/or mortality in COVID-19 patients. Med Mal Infect 50: 397-400, 2020.

102. Toniati P, Piva S, Cattalini M, Garrafa E, Regola F, Castelli F, Franceschini F, Airò $\mathrm{P}$, Bazzani $\mathrm{C}$, Beindorf $\mathrm{EA}$, et al: Tocilizumab for the treatment of severe COVID-19 pneumonia with hyperinflammatory syndrome and acute respiratory failure: A single center study of 100 patients in Brescia, Italy. Autoimmun Rev 19: 102568, 2020

103. Luo J, Rizvi H, Egger JV, Preeshagul IR, Wolchok JD and Hellmann MD: Impact of PD-1 blockade on severity of COVID-19 in patients with lung cancers. Cancer Discov 10 $1121-1128,2020$.

104. Weinkove R, McQuilten ZK, Adler J, Agar MR, Blyth E, Cheng AC, Conyers R, Haeusler GM, Hardie C, Jackson C, et al: Managing haematology and oncology patients during the COVID-19 pandemic: Interim consensus guidance. Med J Aust 212: 481-489, 2020

105. Curigliano G, Cardoso MJ, Poortmans P, Gentilini O, Pravettoni G, Mazzocco K, Houssami N, Pagani O, Senkus E and Cardoso F; editorial board of The Breast: Recommendations for triage, prioritization and treatment of breast cancer patients during the COVID-19 pandemic. Breast 52: 8-16, 2020.

106. Huang SH, O'Sullivan B, Su J, Ringash J, Bratman SV, Kim J, Hosni A, Bayley A, Cho J, Giuliani M, et al: Hypofractionated radiotherapy alone with 2.4 Gy per fraction for head and neck cancer during the COVID-19 pandemic: The princess margaret experience and proposal. Cancer 126: 3426-3437, 2020.

107. Bhowmick NA, Oft J, Dorff T, Pal S, Agarwal N, Figlin RA, Posadas EM, Freedland SJ and Gong J: COVID-19 and androgen-targeted therapy for prostate cancer patients. Endocr Relat Cancer 27: R281-R292, 2020.

108. Shang J, Wan Y, Luo C, Ye G, Geng Q, Auerbach A and Li F Cell entry mechanisms of SARS-CoV-2. Proc Natl Acad Sci USA 117: 11727-11734, 2020.

109. Zhou P, Yang XL, Wang XG, Hu B, Zhang L, Zhang W, Si HR, Zhu Y, Li B, Huang CL, et al: A pneumonia outbreak associated with a new coronavirus of probable bat origin. Nature 579: 270-273, 2020.
110. Mihalopoulos M, Dogra N, Mohamed N, Badani K and Kyprianou N: COVID-19 and kidney disease: Molecular determinants and clinical implications in renal cancer. Eur Urol Focus 6: 1086-1096, 2020

111. Li G, Hu R and Zhang X: Antihypertensive treatment with ACEI/ARB of patients with COVID-19 complicated by hypertension. Hypertens Res 43: 588-590, 2020.

112. Rico-Mesa JS, White A and Anderson AS: Outcomes in patients with COVID-19 infection taking ACEI/ARB. Curr Cardiol Rep 22: 31, 2020.

113. De Spiegeleer A, Bronselaer A, Teo JT, Byttebier G, De Tré G, Belmans L, Dobson R, Wynendaele E, Van De Wiele C, Vandaele F, et al: The effects of ARBs, ACEis, and statins on clinical outcomes of COVID-19 infection among nursing home residents. J Am Med Dir Assoc 21: 909-914.e2, 2020.

114. Ender F, Freund A, Quecke T, Steidel C, Zamzow P, von Bubnoff $\mathrm{N}$ and Gieseler F: Tissue factor activity on microvesicles from cancer patients. J Cancer Res Clin Oncol 146: 467-475, 2020.

115. Barnes GD, Burnett A, Allen A, Blumenstein M, Clark NP, Cuker A, Dager WE, Deitelzweig SB, Ellsworth S, Garcia D, et al: Thromboembolism and anticoagulant therapy during the COVID-19 pandemic: Interim clinical guidance from the anticoagulation forum. J Thromb Thrombolysis 50: 72-81, 2020.

116. Asokan I, Rabadia SV and Yang EH: The COVID-19 pandemic and its impact on the cardio-oncology population. Curr Oncol Rep 22: 60, 2020

117. Lee KCH, Sewa DW and Phua GC: Potential role of statins in COVID-19. Int J Infect Dis 96: 615-617, 2020.

118. Aldinucci D, Borghese $\mathrm{C}$ and Casagrande N: The CCL5/CCR5 axis in cancer progression. Cancers (Basel) 12: 1765, 2020.

119. Patterson BK, Seethamraju H, Dhody K, Corley MJ, Kazempour K, Lalezari J, Pang APS, Sugai C, Mahyari E, Francisco EB, et al: CCR5 inhibition in critical COVID-19 patients decreases inflammatory cytokines, increases CD8 T-cells, and decreases SARS-CoV2 RNA in plasma by day 14 . Int J Infect Dis 103: 25-32, 2021.

120. Patters on BK, Seethamraju H, Dhody K, Corley MJ, Kazempour K, Lalezari JP, Pang AP, Sugai C, Francisco EB, Pise A, et al: Disruption of the CCL5/RANTES-CCR5 pathway restores immune homeostasis and reduces plasma viral load in critical COVID-19. medRxiv: 2020.05.02.20084673, 2020.

121. Choueiri TK, Motzer RJ, Rini BI, Haanen J, Campbell MT, Venugopal B, Kollmannsberger C, Gravis-Mescam G, Uemura M, Lee JL, et al: Updated efficacy results from the JAVELIN Renal 101 trial: First-line avelumab plus axitinib versus sunitinib in patients with advanced renal cell carcinoma. Ann Oncol 31: 1030-1039, 2020.

122. Aeppli S, Eboulet EI, Eisen T, Escudier B, Fischer S, Larkin J, Gruenwald V, McDermott D, Oldenburg J, Omlin A, et al: Impact of COVID-19 pandemic on treatment patterns in metastatic clear cell renal cell carcinoma. ESMO Open 5 (Suppl 3): e000852, 2020.

123. Wang C, Wang J, Shuai L, Ma X, Zhang H, Liu R, Chen W, Wang $\mathrm{X}, \mathrm{Ge} \mathrm{J}$, Wen $\mathrm{Z}$ and $\mathrm{Bu} \mathrm{Z}$ : The serine/threonine kinase AP2-associated kinase 1 plays an important role in rabies virus entry. Viruses 12: 45, 2019.

124. Abdelgalil AA, Al-Kahtani HM and Al-Jenoobi FI: Erlotinib. Profiles Drug Subst Excip Relat Methodol 45: 93-117, 2020.

125. Birk R, Schell A, Aderhold C, Hoch S, Huber L, Mueller CE, Lammert A, Scherl C, Rotter N, Sommer JU and Kramer B: Apoptosis-related proteins are altered by selective tyrosine kinase inhibitors and everolimus in HPV-dependent SCC. Anticancer Res 40: 6195-6203, 2020.

126. El Bairi K, Trapani D, Petrillo A, Le Page C, Zbakh H, Daniele B, Belbaraka R, Curigliano $G$ and Afqir S: Repurposing anticancer drugs for the management of COVID-19. Eur J Cancer 141: 40-61, 2020.

127. Pang J, Xu F, Aondio G, Li Y, Fumagalli A, Lu M, Valmadre G, Wei J, Bian Y, Canesi M, et al: Efficacy and tolerability of bevacizumab in patients with severe Covid-19. Nat Commun 12: 814, 2021

128. Stebbing J, Phelan A, Griffin I, Tucker C, Oechsle O, Smith D and Richardson P: COVID-19: Combining antiviral and antiinflammatory treatments. Lancet Infect Dis 20: 400-402, 2020

129. Jin Z, Zhao Y, Sun Y, Zhang B, Wang H, Wu Y, Zhu Y, Zhu C, Hu T, Du X, et al: Structural basis for the inhibition of SARS-CoV-2 main protease by antineoplastic drug carmofur. Nat Struct Mol Biol 27: 529-532, 2020.

130. Martin WR and Cheng F: Repurposing of FDA-approved toremifene to treat COVID-19 by blocking the spike glycoprotein and NSP14 of SARS-CoV-2. J Proteome Res 19: 4670-4677, 2020. 
131. Dhar D and Mohanty A: Gut microbiota and Covid-19-possible link and implications. Virus Res 285: 198018, 2020.

132. Bottari B, Castellone V and Neviani E: Probiotics and Covid-19. Int J Food Sci Nutr 72: 293-299, 2021.

133. Annweiler G, Corvaisier M, Gautier J, Dubée V, Legrand E, Sacco G and Annweiler C: Vitamin D supplementation associated to better survival in hospitalized frail elderly COVID-19 patients: The GERIA-COVID quasi-experimental study. Nutrients 12: 3377, 2020.

134. Jeon SM and Shin EA: Exploring vitamin D metabolism and function in cancer. Exp Mol Med 50: 1-14, 2018.

135. Munshi R, Hussein MH, Toraih EA, Elshazli RM, Jardak C, Sultana N, Youssef MR, Omar M, Attia AS, Fawzy MS, et al: Vitamin D insufficiency as a potential culprit in critical COVID-19 patients. J Med Virol 93: 733-740, 2021

136. Carpagnano GE, Di Lecce V, Quaranta VN, Zito A, Buonamico E, Capozza E, Palumbo A, Di Gioia G, Valerio VN and Resta O: Vitamin D deficiency as a predictor of poor prognosis in patients with acute respiratory failure due to COVID-19. J Endocrinol Invest 44: 765-771, 2021.

137. Shakoor H, Feehan J, Al Dhaheri AS, Ali HI, Platat C, Ismail LC, Apostolopoulos V and Stojanovska L: Immune-boosting role of vitamins D, C, E, zinc, selenium and omega-3 fatty acids: Could they help against COVID-19? Maturitas 143: 1-9, 2021

138. Akula SM, Abrams SL, Steelman LS, Candido S, Libra M, Lerpiriyapong K, Cocco L, Ramazzotti G, Ratti S, Follo MY, et al: Cancer therapy and treatments during COVID-19 era. Adv Biol Regul 77: 100739, 2020.

139. Tan HW, Mo HY, Lau ATY and Xu YM: Selenium species: Current status and potentials in cancer prevention and therapy. Int J Mol Sci 20: 75, 2018.

140. Chung YH, Beiss V, Fiering SN and Steinmetz NF: COVID-19 vaccine frontrunners and their nanotechnology design. ACS Nano 14: 12522-12537, 2020.

141. Thakkar A, Gonzalez-Lugo JD, Goradia N, Gali R, Shapiro LC, Pradhan K, Rahman S, Kim SY, Ko B, Sica RA, et al: Seroconversion rates following COVID-19 vaccination among patients with cancer. Cancer Cell 39: 1081-1090.e2, 2021.

142. Rodriguez Socarrás M, Gómez Rivas J, Teoh JY, Puente J, Moschini $\mathrm{M}$ and Moreno-Sierra J: The Uro-oncology patient and vaccination against SARS-CoV-2. Eur Urol Open Sci 29: $77-81,2021$
143. Gavriatopoulou M, Ntanasis-Stathopoulos I, Korompoki E, Terpos E and Dimopoulos MA: SARS-CoV-2 vaccines in patients with multiple myeloma. Hemasphere 5: e547, 2021.

144. Han HJ, Nwagwu C, Anyim O, Ekweremadu C and Kim S: COVID-19 and cancer: From basic mechanisms to vaccine development using nanotechnology. Int Immunopharmacol 90: 107247, 2021.

145. von Lilienfeld-Toal M, Rieger C, Giesen N and Wörmann B: Vaccination against SARS-CoV-2 in cancer patients. Onkologe (Berl): 1-6. May 17, 2021. (In German). (Epub ahead of print). doi: 10.1007/s00761-021-00972-1.

146. Mondal M, Guo J, He P and Zhou D: Recent advances of oncolytic virus in cancer therapy. Hum Vaccin Immunother 16: 2389-2402, 2020.

147. Cao GD, He XB, Sun Q, Chen S, Wan K, Xu X, Feng X, Li PP, Chen $\mathrm{B}$ and Xiong MM: The oncolytic virus in cancer diagnosis and treatment. Front Oncol 10: 1786, 2020.

148. Nguyen HM, Guz-Montgomery K and Saha D: Oncolytic virus encoding a master pro-inflammatory cytokine interleukin 12 in cancer immunotherapy. Cells 9: 400, 2020.

149. Wang G, Kang X, Chen KS, Jehng T, Jones L, Chen J, Huang XF and Chen SY: An engineered oncolytic virus expressing PD-L1 inhibitors activates tumor neoantigen-specific T cell responses. Nat Commun 11: 1395, 2020.

150. Ji W, Li L, Zhou S, Qiu L, Qian Z, Zhang H and Zhao P: Combination immunotherapy of oncolytic virus nanovesicles and PD-1 blockade effectively enhances therapeutic effects and boosts antitumour immune response. J Drug Target 28: 982-990, 2020.

151. Duijf PHG: Low baseline pulmonary levels of cytotoxic lymphocytes as a predisposing risk factor for severe COVID-19. mSystems 5: e00741-20,2020.

152. Challenor S and Tucker D: SARS-CoV-2-induced remission of Hodgkin lymphoma. Br J Haematol 192: 415, 2021.

This work is licensed under a Creative Commons Attribution-NonCommercial-NoDerivatives 4.0 International (CC BY-NC-ND 4.0) License. 